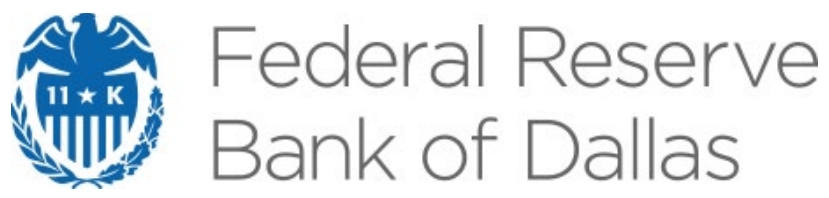

\title{
The Impact of the COVID-19 Pandemic on the Demand for Density: Evidence from the U.S. Housing Market
}

Sitian Liu and Yichen Su

Working Paper 2024

August 2020 (revised October 2020)

Research Department

https://doi.org/10.24149/wp2024r1

Working papers from the Federal Reserve Bank of Dallas are preliminary drafts circulated for professional comment. The views in this paper are those of the authors and do not necessarily reflect the views of the Federal Reserve Bank of Dallas or the Federal Reserve System. Any errors or omissions are the responsibility of the authors. 


\title{
The Impact of the COVID-19 Pandemic on the Demand for Density: Evidence from the U.S. Housing Market ${ }^{*}$
}

\author{
Sitian $\mathrm{Liu}^{\dagger}$ and Yichen Su${ }^{\ddagger}$ \\ This draft: October 17, 2020 \\ First draft: July 27, 2020
}

\begin{abstract}
Cities are shaped by the strength of agglomeration and dispersion forces. We show that the COVID-19 pandemic has re-introduced disease transmission as a dispersion force in modern cities. We use detailed housing data to study the impact of the COVID-19 pandemic on the location demand for housing. We find that the pandemic has led to a reduced demand for housing in neighborhoods with high population density. The reduced demand for density is driven partially by the diminished need of living close to jobs that are telework-compatible and the declining value of access to consumption amenities. Neighborhoods with high pre-COVID-19 home prices also see a greater drop in housing demand. While the national housing market recovered after June, we show that the pandemic's negative effect on the demand for density persisted and strengthened, indicating that the change in the demand for density has lasted beyond an aggregate recovery of housing demand.
\end{abstract}

Keywords: COVID-19, Pandemic, Density, City, Neighborhood, Housing, Location, Telework, Amenity

JEL Codes: R2, R3, I1

\footnotetext{
* The views expressed in this article are those of the authors and do not necessarily represent the views of the Federal Reserve Bank of Dallas or the Federal Reserve System. Please click here to download the latest version.

†Sitian Liu, Department of Economics, Queen's University, Email: sitianliu@econ.queensu.ca.

${ }^{\ddagger}$ Yichen Su, Federal Reserve Bank of Dallas, Email: yichensu@outlook.com.
} 


\section{Introduction}

The desirability and structure of cities are shaped by the strength of agglomeration and dispersion forces (Ahlfeldt et al. 2015). During much of human history, the dispersion forces such as communicable disease and overcrowding kept the sizes of settlements and cities from growing too large (Glaeser, 2011). Thanks to the infrastructure and medical advancements, these dispersion forces have been greatly reduced. With these dispersion forces in check, the agglomeration effect of human interaction for production and consumption is allowed to flourish, leading to the creation of large cities and dense neighborhoods (Glaeser et al., 2000, Glaeser and Gottlieb, 2009).

However, the COVID-19 pandemic has re-introduced the danger of disease transmission as a potentially serious dispersion force in modern cities (Autor and Reynolds, 2020). Because of the contagious nature of the disease, office workers no longer commute to crowded urban locations for work, and instead conduct businesses virtually at home (Bartik et al., 2020, Mas and Pallais, 2020; Bick et al. 2020). Consumption amenities such as restaurants have also seen much fewer visits, owing to policy mandates or consumers' concerns over the potential exposure to the virus in indoor public spaces (Allcott et al., 2020, Chen et al., 2020; Chetty et al., 2020; Cox et al., 2020). While some are hopeful that foot traffic may recover quickly, many would argue that the aversion to crowded venues could continue well into the future ${ }^{1}$ Many companies even started to allow some of their employees to work from home permanently $\left.\right|^{2}$ If work-from-home becomes more prevalent and visiting amenities continues to be curbed, the desirability of large cities and dense neighborhoods would remain reduced for a long time to come.

In this paper, we use detailed geocoded housing data to study the spatial impact of the COVID19 pandemic on location demand for housing across neighborhoods within cities and across cities in the U.S. We find that the COVID-19 pandemic has led to a reduced demand for housing closer to central cities and in neighborhoods with higher population density.

Immediately after the pandemic started, home sales in central cities and dense neighborhoods dropped considerably more than other locations since the outbreak of COVID-19. Meanwhile, although new listings have dropped as well in aggregate since the outbreak, we do not find differences

\footnotetext{
${ }^{1}$ See Atlanta Fed Macroblog: https://www.frbatlanta.org/blogs/macroblog/2020/05/28/firms-expect-workingfrom-home-to-triple. See also Dallas Fed Texas Business Outlook Survey August 2020 Special Questions: https://www.dallasfed.org/research/surveys/tbos/2020/2008q.aspx.

${ }^{2}$ https://www.npr.org/2020/06/22/870029658/get-a-comfortable-chair-permanent-work-from-home-is-coming.
} 
in the decline by location characteristics such as distance to downtown or density $]^{3}$ Inventory increased more in dense and central neighborhoods, indicating that the pandemic immediately started to change people's demand for density after the initial outbreak.

As the pandemic continued and aggregate housing sales fully recovered, the reduced demand for density not only did not recover but deepened. New listings in central cities started to soar compared to the suburbs. Home inventory in the central cities increased while inventory in the suburbs plummeted, indicating that the shifting demand toward the suburbs continued well into the pandemic. Regression analysis shows that these results are not driven by differential case rates.

We make several conjectures of potential reasons behind the decline in demand for density, and test these conjectures in the data.

1. Dense neighborhoods tend to be close to large job centers (e.g., central business districts), which tend to have a greater share of telework-compatible jobs $4^{4}$ As the pandemic kicks in and people start to work from home, the need for living in these neighborhoods becomes obsolete. Therefore, the demand for central locations could diminish.

2. Dense neighborhoods tend to have good access to a large selection of consumption amenities.$^{5}$ Because of the need for social distancing, people are substituting away from visiting restaurants with home production. As a result, the value of living closer to consumption amenities may decline, leading to lower demand for neighborhoods with premium access to amenities.

3. Dense neighborhoods tend to have higher costs of housing (Brueckner, 2011) ${ }^{6}$ The demand for density had been rising in the U.S. before the pandemic (Autor and Reynolds, 2020), as large cities and dense neighborhoods were increasingly sought after 7 As the driving forces behind such demand vaporize because of the need for social distancing, the value of bearing

\footnotetext{
${ }^{3}$ One alternative explanation of higher-density areas seeing a greater decline in sales is that these places are more likely to be locked down because of the pandemic. Our results are robust to the concern because we control for MSAspecific effects of the pandemic, which could account for differential likelihoods of lock-down across MSAs. Moreover, if there are differential likelihoods of lock-down across neighborhoods, new listings should also exhibit heterogeneity, which we do not find.

${ }^{4}$ Table A1 in the Appendix shows that locations with higher population density tend to have a higher share of telework-compatible jobs in the surrounding areas.

${ }^{5}$ Table A1 shows that locations with higher population density tend to be close to a larger number of restaurant amenities per capita.

${ }^{6}$ Table A1 shows that locations with higher population density tend to have higher pre-COVID-19 home prices.

${ }^{7}$ Besides access to (short commutes) to jobs and access to consumption amenities, dense locations are able to support public amenities such as parks, museums, and easier access to events and nightlife.
} 
high housing costs to be in these locations also decreases. Therefore, there could be an exodus of housing demand from locations of high house prices.

4. People may become more concerned about living in locations with high density per se due to the pandemic. First, people may perceive that dense locations are more prone to disease transmission due to overcrowding. For example, people are much more likely to bump into each other or share an elevator in a high-rise urban apartment than in suburban neighborhoods with single detached houses. Second, dense neighborhoods are likely to rely heavily on public transit (e.g., buses, rails, and subways). Given the confined space of public transport vehicles, people may want to avoid settling in locations where residents rely mostly on public transit: 8

The empirical evidence lends support to all of the conjectures. We find that the pandemic lowered home sales more and increased inventory in neighborhoods with a greater share of teleworkcompatible jobs nearby, more consumption amenities, higher pre-pandemic home prices, and lower income levels. After holding these observables constant, we still find that housing sales growth is lower in locations with higher residual density due to the pandemic, which suggests that home buyers may be concerned about density per se owing to the fear of viral transmission in crowded places.

A potential alternative explanation for the disproportionate drop in home sales and rise in inventory near city centers and dense neighborhoods is that these locations may have higher case rates and be more prone to lock-down policies, or that they may have more cautious populations (Alexander and Karger, 2020). A greater decline in home sales may, therefore, reflect a freeze in buyers' propensity to buy homes due to COVID-19, which is not indicative of changes in the underlying location demand. If the likelihood of lock-down is correlated with location characteristics such as distance to downtown and density, the correlation between the change in home sales and inventory and these location characteristics may simply reflect a "lock-down effect," not necessarily a change in the underlying demand for locations. In light of these potential concerns, we argue that our findings are likely to reflect changes in location demand for the following reasons.

First, in our neighborhood-level analysis, we account for potentially different post-pandemic changes in all our housing market outcomes, including sales and inventory, at the metropolitan

\footnotetext{
${ }^{8}$ Ideally, we would like to treat the point regarding the reliance on public transit as a separate conjecture and test it separately from density. As we attempt to analyze its role, we find that the public transit usage rate is extremely correlated with residential density at the neighborhood level. The residual variation in public transit reliance after controlling for density is too small to have enough power to identify its effect on housing demand.
} 
statistical area (MSA) level. Therefore, the differences in the prevalence of COVID-19 across cities are not likely to affect our results. It is still possible that different areas within the same MSA could experience different degrees of the lock-down effect due to different levels of the seriousness of the outbreak. We attempt to account for such variation by including county-level case rates as an additional location characteristic.

Second, even though new listings have fluctuated with sales in aggregate, new listings does not decrease more in places with higher density in the beginning of the pandemic. If our results on sales and inventory are driven by a lock-down effect, new listings would vary in the same direction as sales or at least not increase more in denser locations. The data show an opposite finding. After June, new listings actually increased disproportionately in places with high density. The only possible explanation for new listings to be higher in higher-density locations is that the current homeowners in these locations were looking to sell, consistent with a reduced demand for density.

Besides within-city shift in housing demand, we also examine the shift in demand across cities. We find housing demand has been shifting from large and expensive cities to smaller and cheaper cities, although the magnitude of the shift appears to be far smaller than the shift from central cities to the suburbs. This is consistent with the rise in working-from-home, since many workers who work for firms in expensive cities are no longer required to live in the same cities as they work. Indeed, we find cities with a higher share of telework-compatible jobs see a larger increase in new listings and inventory, indicating a outbound shift of housing demand by workers who can work from home.

How long the effect of the pandemic on the demand for density will last likely depends on how long the pandemic will last and how long people will avoid commuting to work or visiting restaurants and stores. As the COVID-19 crisis eventually ends, and the fear of the virus is lifted, demand cities would very likely to recover. After all, the demand for consumption amenities would likely bounce back. However, as many workers and firms have reported to have permanently shifted to working from home, the reduced future commuting trips into the cities may have a negative effect on the future demand for high-density and central city neighborhoods.9 $9^{9}$ With so much unknown, the long-term effects of COVID-19 on cities remain far from certain.

\footnotetext{
${ }^{9}$ Survey results in Bartik et al. (2020) suggest more than $35 \%$ of firms think that $40 \%$ or more of the current switch to remote working will be permanent. Atlanta Fed Survey of Business Uncertainty suggests that $27 \%$ of the firms expect employees will be able to work from home at least one day per week. Dallas Fed Texas Business Outlook Survey Special Questions suggest that firms expect that $20.6 \%$ of the employees will work from home after the pandemic.
} 


\section{Data}

We combine several data sources for the analysis. The main outcome variables include sales, new listings, median home sales prices, rental prices, and online viewings of properties, which are sourced from Redfin Data Center, Zillow Research, and Realtor.com. We obtain ZIP code-, county-, and MSA-level characteristics from the American Community Survey (ACS), the National Historical Geographic Information System (NHGIS), and the Zip Code Business Patterns (ZCBP).

\subsection{Sales, Listings, Inventory and Prices}

We obtain information on home sales, new listings, inventory, and median home sale value at a monthly frequency at the ZIP code, county, MSA, and national levels from Redfin Data Center from the year 2016 to August 2020. Redfin is an online real estate brokerage firm, with direct access to local multiple listing services (MLS). Through the local MLS listings, Redfin provides information on all broker-listed homes, 10

It is noteworthy that ZIP code-level variables are constructed with pooled three-month lagged data. For example, a ZIP code-level number of home sales in January, 2020 includes total home sales recorded from November 1, 2019 to January 31, 2020. Median sale price is the median price of homes sold in the three-month period. Variables constructed at the county level or above are one-month values only.

\subsection{Online Views of Homes}

Besides real sales and listings information, we use the online views of properties on Realtor.com as an alternative tracker of housing demand. Realtor.com is the largest real estate listing website in the U.S. They provide the ratio between the number of website views on the average property in each ZIP code and the number of website views on the average property nationwide at a monthly frequency between 2017 and September 2020. We use this monthly reported value as an alternative measurement for the underlying demand for housing in each ZIP code location 11

\footnotetext{
${ }^{10}$ The data include homes in foreclosure. Homes in pre-foreclosure, properties on sale outside of MLS (e.g., Craigslist), and commercial properties are excluded from the data.

${ }^{11}$ The advantage of using online views is that it is not subject to the lock-down effect of the pandemic, since online views of properties are conducted virtually. The drawback of this measure is that people might simply browse properties without seriously considering purchasing a house.
} 


\subsection{Rental Prices}

We obtain monthly rental price data from the Zillow Observed Rent Index (ZORI) released by Zillow Research. The variable is a smoothed measure of the typical observed market rents in a given region. ZORI is a repeat-rent index that is weighted to the rental housing stock to ensure representativeness across the entire market, not just those homes currently listed for rent ${ }^{12}$ We use the monthly rent data from 2016 to September 2020.

\subsection{Local Characteristics}

We obtain local characteristics such as population density, income level, racial composition, public transit usage intensity from the summary tables of the 2013-2017 ACS through the NHGIS Manson et al. 2020). The data come at the ZIP code, county, and MSA levels.

For each ZIP code, we calculate the Euclidean distance to the closest downtown. We geocode all the downtowns using the output of Holian and Kahn (2015).

\subsection{Telework-Compatibility}

We compute the share of jobs that are telework-compatible for each ZIP code based on the spatial distribution of occupations, and an assignment of telework-compatibility for each occupation. Dingel and Neiman (2020) and $\mathrm{Su}(2020)$ use O*NET occupation characteristics to evaluate each occupation's suitability for telework, and assign a telework indicator to each occupation. We use the telework indicator developed by Dingel and Neiman for the main analysis 13

We use data from the 2016 ZCBP for local job distributions. The ZCBP comes at the NAICS level. We use the industry to occupation crosswalk to impute the local job distribution for each occupation. Based on the spatial job distribution at the ZIP code level and each occupation's telework-compatibility, we calculate the share of jobs within a 3-mile radius of each ZIP code that are telework-compatible. We use the ZIP Code Tabulation Area (ZCTA) Distance Database from the NBER website for distance measure between ZIP codes 14

We obtain MSA-level occupation compositions using micro-data from the 2013-2017 ACS ob-

\footnotetext{
${ }^{12}$ The index is dollar-denominated by computing the mean of listed rents that fall into the 40th to 60 th percentile range for all homes and apartments in a given region, which is once again weighted to reflect the rental housing stock.

${ }^{13}$ In Table A3 we show the results using $\mathrm{Su}(2020)$ 's calculation. The estimation results are almost identical.

${ }^{14}$ https://data.nber.org/data/zip-code-distance-database.html.
} 
tained from the IPUMS (Ruggles et al., 2020). Specifically, for each MSA, we estimate the share of full-time workers aged from 25 to 69 in each occupation. Combined with the telework indicator for each occupation, we estimate the share of workers who are in telework-compatible occupations for each MSA.

\subsection{Amenities (Restaurants)}

We use the 2016 ZCBP to estimate the number of restaurants by ZIP code in 2016. Using a similar method with which we construct the spatial profile of jobs, we calculate the number of restaurants (establishment with NAICS code 7225xx) within a 3-mile radius of each ZIP code. We then calculate the per capita number of restaurants (i.e., the number of restaurants within a 3-mile radius divided by the population of the ZIP code).

\subsection{County-Level Case Rate of COVID-19}

We download county-level case rates of COVID-19 from the Opportunity Insights Economic Tracker, which provides the source data for Chetty et al. $(2020) \cdot 15$

\subsection{SafeGraph Weekly Patterns Data}

We use data of SafeGraph weekly patterns from January to September 2020 to analyze the differential changes in traffic to different types of urban amenities in the wake of the COVID-19 pandemic. The change in traffic patterns can be observed with detailed geocode, and thus allow us to demonstrate the overall and spatially differential change in traffic based on the distance to downtown.

SafeGraph Inc. is a geospatial data analysis firm that collects spatial behaviors of mobile devices. The firm provides aggregated, anonymized data. In this paper, we analyze the visiting patterns to business establishments. The dataset contains weekly number of visits to each point-of-interest in SafeGraph's database. Each point-of-interest is assigned a NAICS category. With the NAICS code, we can classify each type of point-of-interest into different types, such as offices, restaurants, grocery stores, etc. Each point-of-interest has a block-group code, provides highly geolocation information of the business.

\footnotetext{
${ }^{15}$ https://opportunityinsights.org.
} 


\section{Empirical Analysis and Results}

\subsection{The Timing of the COVID-19 Pandemic in the U.S.}

The COVID-19 cases started to spike in the latter half of March 2020 in the U.S ${ }^{16}$ Studies have also documented that physical movements and hours worked were dramatically cut back starting around the third week of March 2020, using data on people's real-time movements and business establishment activities (Atkinson et al., 2020, Kurmann et al., 2020) 17 Although the virus has started to spread in many other parts of the world before mid-March, the decline in people's physical movements and hours worked was small in the U.S. After the initial outbreak in late March and peak April, economic activities started to partially recover starting in May, but still significantly below pre-pandemic levels by the end of our data period 18 New cases and deaths continued to spike in multiple areas across the U.S. as of October of 2020.

Since our housing data come at a monthly frequency, we define months after March in 2020 as the period after the outbreak of COVID-19. The key assumption of our empirical analysis is that the observed housing market outcomes should have been the same as they were in these respective months in previous years, based on earlier data. The differences between the observed outcomes in months after March in 2020 and these same months in previous years reveal the impact of COVID-19 on the housing market. We describe the empirical approach and its identification assumption with more details later in this section.

\subsection{The Aggregate Impact of COVID-19 on the U.S. Housing Market}

We start our analysis with the aggregate impact of the pandemic on the housing market. Figure 1 presents the log number of homes sold, log number of new listings, log inventory, log number of days on the market, log median sale price, and log rental price at the national level by month in 2019 and 2020. The number of sales, new listings, and inventory all dropped dramatically in April 2020 relative to 2019. Such wild swings are likely to reflect the sudden lock-down effects at the beginning of the pandemic and the effects of the subsequent re-openings on the housing markets. The aggregate

\footnotetext{
${ }^{16}$ https://coronavirus.jhu.edu/data/new-cases.

${ }^{17}$ Many technology firms post their data online, which confirms the sharp timing documented in the literature. One example is the Google Mobility Reports on the United States: https://www.google.com/covid19/mobility.

${ }^{18}$ The trajectory of economic activities over the course of the pandemic can be shown in the Mobility and Engagement Index developed by the Federal Reserve Bank of Dallas: https://www.dallasfed.org/research/mei.
} 
housing and rental prices saw a mild dip in May and April respectively.

However, since June, as economic activities partially recovered, the housing market rebounded robustly. To the surprise of many, the aggregate housing market activities not only recovered fully from the initial decline, the nation posted record sales numbers in July. The rising sales is accompanied by a dramatic decline in inventory and a rise in median sales values after June, signaling is surging demand for owner-occupied homes. The declining mortgage rates after the Fed's interest rate cut could have partially contributed to the rising aggregate home purchasing, as the cost of mortgage decreased 19

Next, to analyze the change in the demand for density, we conduct our main analysis by drilling down into finer geography, and show the heterogeneous effects based on local characteristics like density.

\subsection{Neighborhood-Level Analysis}

First, we use a series of location-specific housing market outcomes over the months in 2020 to demonstrate that demand for central city housing dropped disproportionately in the wake of the pandemic and continued to lag behind the suburbs.

Figure 2 shows the 12-month percentage growth of sales, new listings, inventory, and median home values for each month from 2019 to 2020, by distance to downtown for the most populous 25 MSAs in the US. In the beginning of the pandemic from March to May, sales and listing activities plummeted across all neighborhoods, which likely reflects the effect of the initial lock-down and the freezing of most transactional activities. Notably, sales in central city neighborhoods dropped disproportionately compared sales in the suburban neighborhoods. In contrast, new listings in central cities dropped at a similar rate as new listings in the suburbs. This leads to a divergence in trends in inventory, where inventory in the suburbs started to drop while inventory in the central cities remained flat. The diverging trends in inventory indicates that housing demand began to shift to the suburbs during the initial three months of the pandemic. Median sales value of homes in central cities, however, did not show a significant dip during the initial months. This may be because it

\footnotetext{
${ }^{19}$ The rising demand for owner-occupied home could also be driven by a reduced demand for central city rental apartment. The suggestive evidence for this explanation is that as inventory for single-family homes dropped dramatically over the July and August, the inventory of condominiums remain relatively stable over time, indicating that the drop in mortgage did not spur much of a demand surge in condominium properties. See Figure A1 in the appendix. This suggests that the rising demand for homes may have been partially geography-based, not entirely driven by the lowering of rates.
} 
takes time for housing price to adjust, or a selection effect of homes being sold during a pandemic.

Starting from June, the aggregate housing market recovered robustly, with home sales and new listing rising sharply. New listings in central cities started to increase faster than new listings in the suburbs in June, and the gap between new listings in central cities and suburbs continued to widen in July and August. This indicates a large number homeowners in the central cities were looking to sell their homes, compared to the suburbs. The wave of sell-offs in the central cities is accompanied by a continued widening of inventory gap in the central cities and suburbs, with the yearly inventory growth rate reaching a positive number in the central cities and inventory shrinking by more than $40 \%$ in the outer suburbs. A diverging trends can be observed in median sales value, but the trajectories of the three curves are more blurry, possibly due to a slow home price adjustment process. Nonetheless, The massive sell-offs and the rising inventory in the central cities and the rapidly declining inventory in the suburbs suggest that demand for housing has quickly shifted toward the suburbs since the pandemic.

\subsubsection{Regression Analysis}

In the next part, we dig further into the data and try to examine to what extent the sudden shift toward the suburbs has been driven by the decline in the demand for density. Next, we would further unpack the driving forces behind the reduced demand for density.

We first discuss how we use a regression model to estimate the heterogeneous impact of the pandemic on the housing market across neighborhoods within MSAs. From here on, we interchangeably refer to MSAs as cities.

The empirical specification takes the following form:

$$
\begin{aligned}
\log \left(s_{n c m y}\right) & =\beta_{1} \text { After }_{m y} \cdot x_{n c}+\beta_{2} \text { After }_{m y} \cdot \log \left(\text { CaseRate }_{n c}\right) \\
& + \text { After }_{m y} \cdot \lambda_{c}+\pi_{m y}+\delta_{n m}+\gamma_{n y}+\epsilon_{n c m y}
\end{aligned}
$$

where $s_{n c m y}$ is a housing market outcome, including home sales, new listings, inventory, and median home value, in neighborhood $n$ within MSA $c$ in month $m$ of year $y 20$ After $m y$ is a dummy variable that indicates the outbreak of COVID-19, which takes 1 if $m \geq 4$ and $y=2020$, and 0 otherwise.

\footnotetext{
${ }^{20}$ We add 1 to each outcome variable before taking log.
} 
$x_{n c}$ denotes some neighborhood characteristic of interest, such as density, distance to city center, etc., and we add additional characteristics in the regression equation interacted with After $r_{m y}$. We control for the county-level average case rate between April and August in 2020 of neighborhood $n$ $\left(\right.$ CaseRate $\left._{n c}\right)$, which could absorb some unobserved factors that are spatially correlated with the severity of local spread. For instance, activities related to the housing market may be more likely to pause in areas with higher case rates because of lock-down policies or consumers' concerns.

For that purpose, we also control for MSA-specific effects of the pandemic using After $m y \cdot \lambda_{c}$. If the effect of lock-down varies by MSA, variation across neighborhoods over time within cities allows us to identify the effect of local characteristics on housing outcomes. $\pi_{m y}$ represents a time fixed effect, which absorbs common shocks in month $m$ of year $y$ faced by all housing markets in the country. $\delta_{n m}$ represents month-varying shocks to the housing market in neighborhood $n$, such as seasonal trends in housing activity ${ }^{21} \gamma_{n y}$ represents year-varying shocking to the neighborhood's housing market, such as local economic shocks. The coefficient of interest is $\beta_{1}$, which represents the differential effects of the pandemic across neighborhoods of different characteristics ${ }^{22}$

County-level analysis We first conduct the analysis at the county level. This is because Redfin Data Center provides monthly data at the county level-although ZIP code-level data are also monthly, the variables are constructed with pooled three-month lagged data.

Panel A in Table 1 presents the estimates of $\beta_{1}$. We control for the interaction of county-level log income level and share of whites. Each of the column presents regression results of a different housing market outcome variable. We find that home sales decline more in counties with higher population density. Moreover, holding population density constant, we find that home sales decline more in counties with higher pre-COVID house prices. This indicates that the pandemic has shift housing purchasing activities toward less dense and cheaper locations. The pandemic has spurred more new listings in places with higher density and more expensive neighborhoods, suggesting sell-offs occurring in denser and more expensive neighborhoods. With the pandemic spurring less sales and more new listings in denser and more expensive neighborhoods, it is not surprising that we also find that the pandemic effect on inventory is more positive in denser and more expensive neighborhoods. However, we do not find a heterogeneous effect on median sales value by density and pre-COVID

\footnotetext{
${ }^{21}$ Note that we allow the seasonal trends to differ potential by neighborhood.

${ }^{22}$ We weight observations by neighborhood population.
} 
home price.

Decreased demand for density persists despite an aggregate recovery in sales As mentioned in the introduction, one might speculate that such overall effects of the pandemic are mainly driven by the immediate aftermath of the outbreak, and the reduced demand for density may have rebounded as the housing market recovers. We examine this by looking further into the timing of the effect of pandemic on all the four outcome variables.

In panel B of Table1, we decompose the timing of these effects. Instead of interacting the dummy

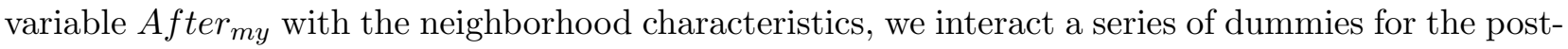
pandemic months, each representing a month after the start of the pandemic. We show that the heterogeneous effects on sales were very strong in the initial periods of the pandemic, and the effect dwindled over time. In contrast, the heterogeneous effects on new listings were not pronounced in the beginning, but started to pick up as the pandemic progressed. The initially muted heterogeneity in new listings may have been a result of the lock-down effects. The would-be sellers in denser locations were putting off their plans to sell at the height of the pandemic, even if they were more willing to sell. The would-be buyers of central city homes, however, can easily put off their plan to buy, if they no longer wished to purchase. This could explain the initial heterogeneous effect on sales, but not new listings. Over time, as more and more home owners in denser neighborhoods put up their homes on sale, the effects got more pronounced. As selling activities increased, the effects on sales became increasingly muted.

As column (3) shows, the heterogeneous effects on inventory clearly have clearly strengthened over time, implying that the shift in housing demand did not occur abruptly, but rather manifested itself gradually over time. We can see that the heterogeneous effects on median home value increased over time, though the pattern is not very robust statistically.

Figure 1 shows that national home sales have partially recovered to levels in 2019 by June. In other words, although the demand for housing recovered robustly in aggregate since June, we do not find that home sales in counties with high population density recover faster. Furthermore, new listings in denser locations started to climb a few months into the pandemic. As a result, The results suggest that the reduced demand for dense neighborhoods not only persisted through the aggregate recovery, but appeared to have strengthened. 


\section{ZIP code-level analysis: Unpacking the reasons for the change in location demand To}

explore the potential mechanisms that drive the differential sale reductions across neighborhoods, we move to ZIP code-level analysis. The upside of the ZIP code-level analysis is that we can examine to what extent the differential effects of the pandemic on housing demand across neighborhoods are driven by spatial variation in the access to jobs, telework-compatibility, and the access to consumption amenities. A potential downside of moving to the ZIP code level is that variables on home sales, new listings, inventory, and sale prices at the ZIP code level are constructed with pooled three-month lagged data. It may potentially reduce the timing-sensitivity of our estimates. As in county-level analysis, we control for county-level case rates and MSA-specific effects of the pandemic. April is dropped from the sample, because the Zip Code level data are pooled. April data pool February, March and April. Two-third of the data in April were actually generated before the pandemic.

We estimate Equation 1 at the ZIP code level and, the estimates of $\beta_{1}$ are presented in Table $2{ }^{23}$

Panel A shows the baseline results where the only two covariates included are log distance to downtown and log density. The results suggest that the pandemic led to less home sales and higher inventory in neighborhoods closer to the central city with higher population density. Sales value dropped lower in places with higher density. The coefficients on new listings are less pronounced.

In Panel B, we add the interactions between After $_{m y}$ and (i) log number of jobs within 3 miles of a ZIP code over the population of the ZIP code, (ii) log share of telework-compatible jobs, and (iii) $\log$ number of restaurants within 3 miles of a ZIP code over the population of the ZIP code. Including these terms slightly attenuates the difference in the effect of the pandemic on sales by density, suggesting that some of the reduced demand for density could be attributed to the reduction in people's demand for living close to work and amenities. Indeed, the estimated coefficients suggest that the pandemic's negative effect on home sales is greater in neighborhoods with more telework-

\footnotetext{
${ }^{23}$ Figure A2, A3, A4, A5 presents binned scatter plots of the effect of the pandemic sales, new listings, inventory, median home value against several neighborhood characteristics by ZIP code, including (i) distance to the central city, (ii) population density, (iii) share of nearby jobs (within 3 miles of a ZIP code) that are telework-compatible, (iv) number of restaurants per capita (as a measurement of consumption amenity), (v) pre-COVID house price, and (vi) income. We find greater home sales declines in neighborhoods closer to the central city, and with higher population density, higher shares of telework-compatible jobs, more restaurants, higher pre-COVID house price, and lower income level. We obtain the ZIP code-level effect of the pandemic on log sales by estimating $\beta_{z c}$ in the following regression:

$$
\log \left(s_{z c m y}\right)=\beta_{z c} \text { After }_{m y}+\lambda_{c}+\pi_{m y}+\delta_{z m}+\gamma_{z y}+\epsilon_{z c m y}
$$

where all the variables are defined as in Equation 1 To construct the figures, we divide the $x$ variable that measures a neighborhood characteristic into 20 bins, and plot the mean values of $x$ and $y$ variables within each bin, controlling for the average case rate of each neighborhood between April and August 2020.
} 
compatible jobs and restaurants nearby. The same consistent effects can be seen for both new listings and inventory. Places with higher share of telework jobs and more restaurants are seeing more attempts to sell and a larger growth in inventory. Again, the effect on prices are less pronounced. The effect on rent is more negative in higher-density neighborhoods and places with higher share of telwork-compatible jobs, although the results are quite noisy.

In Panel C, we investigate the role of pre-COVID house prices and income level of a neighborhood. Based on the results in sales and inventory, We find that the pandemic lowers housing demand for neighborhoods with higher house prices. Holding price constant, the effect is greater in neighborhoods with lower income levels. Nevertheless, controlling for house price and income level, we do not find differences across neighborhoods by racial composition.

In Panel D, we include all the observable location characteristics, and we still find statistically significant estimates on most the interaction terms, for sales and inventory. Including all the control variables attenuates difference in the effects of the pandemic by density. Interestingly, we still see that the pandemic led to reduced sales in neighborhoods with high density. This suggests that would-be buyers are more wary about buying homes in a high-density neighborhood, even holding other neighborhood features equal.

Table 3 shows the decomposition of timing of the effects at Zip Code level. To simplify the table, we group the post-pandemic months into two groups: May - June and July - August. April is dropped from the sample, because the Zip Code level data are pooled. The coefficients in this table further show that the changed demand for city characteristics such as access to telework-compatible jobs and restaurants did not occur abruptly, but rather kicked in gradually and become more pronounced after July.

\subsubsection{Corroborating Evidence from the Change in Traffic Patterns}

With the regression results, we have shown that the housing demand for neighborhoods with access to telework-compatible jobs and consumption amenities (restaurants) saw a dramatic decline. In the wake of the pandemic, home demand has been shifting toward cheaper and less accessible locations. The underlying driving force for a decreased demand for these previously prime locations is that the value of visiting city locations (either workplace or amenities) has become diminished due to safety caution over the virus. 
Figure 4 provides corroborating evidence that visits to business establishments, including offices and consumption amenities, plummeted after the outbreak, and only partially recovered as the pandemic dragged on. Each curve represents the number of visits of the respective month in 2020 divided by the number of visits recorded in January 2020. Interestingly, the drop in traffic is much larger in establishments in the central cities. The disproportionate drop in traffic to offices could reflect the higher proportion of jobs in the central cities that are telework-compatible. The disproportionately drop in traffic to restaurants, grocery stores, gym, etc. could be due to a stricter lock-down and re-opening policies, more cautious attitude of the public in the urban areas, or a result of migration of out of city centers.

\subsection{MSA-Level Analysis}

The results in the previous section suggest that the pandemic could have changed people's demand for residential locations within cities. Next, we examine whether the pandemic has affected the demand for certain characteristics of cities.

First, we show some summary statistics. Figure 3 shows the 12-month percentage growth of sales, new listings, inventory, and median home values for each month from 2019 to 2020, by the size of the MSA in the US. We divide the MSAs into three categories: the largest 25 MSAs, 25-100th largest MSAs, and the other MSAs.

We can see that in the beginning of the pandemic from March to May, sales and listing activities plummeted across all cities. Sales in the largest cities dropped disproportionately compared sales in the others. New listings also dropped at a disproportionate rate in the largest cities, likely due to a lockdown effect. The trends of inventories in cities of different sizes have diverged, but seem to have not diverged in the same dramatic fashion as between central cities and suburbs. Median sales values were quite noisy at the beginning of the pandemic.

However, starting from June, as the aggregate housing market recovered. New listings in the largest cities started to increase faster than new listings in smaller cities. Inventory in the largest cities continued to drop slower than the smaller cities. A diverging trends can be also observed in median sales value across cities, but only after June. Judging from the summary statistics, the shifting of housing demand from largest cities to smaller cities has been happening, but has been in much smaller magnitude than the shifting of housing demand from central cities to the suburbs. 


\subsubsection{Regression Analysis}

To further dissect the shift in housing demand across MSA, we use the following empirical specification:

$$
\begin{aligned}
\log \left(s_{c m y}\right) & =\alpha_{1} \text { After }_{m y} \cdot x_{c}+\alpha_{2} \text { After }_{m y} \cdot \log \left(\text { CaseRate }_{c}\right) \\
& +\pi_{m y}+\delta_{c m}+\gamma_{c y}+\epsilon_{c m y}
\end{aligned}
$$

where $s_{c m y}$ is a housing market outcome of MSA $c$ in month $m$ of year $y ; x_{c}$ is a city characteristic; CaseRate $_{c}$ is the average case rate of city $c$ between April and August 2020; $\delta_{c m}$ is a city $\times$ month

fixed effect; $\gamma_{c y}$ is a city $\times$ year fixed effect. Other variables are defined as in Equation $1{ }^{24}$ The coefficient of interest is $\alpha_{1}$, which estimates the differential effects of the pandemic across cities of different characteristics. Identification is based on variation across cities over time.

Table 4 presents the estimates of $\alpha_{1}$. The results suggest that, similar to differences across neighborhoods, home sales decline and inventory increases relatively more in cities with higher preCOVID house prices. We also see new listings and inventory increase more in cities with higher share of telework-compatible workers. Interestingly, we find that new listings decrease less in cities with a larger share of workers in occupations that are telework-compatible. These results seem intuitive, since the work-from-home arrangement allowed many workers to relocate in a different city from the city that they work in. Table 5 presents estimates with a decomposition of timing. The results appear to be less robust compared to the within-city analysis.

\section{Conclusion}

We study the impact of the COVID-19 pandemic on the demand for neighborhoods and cities, using highly localized data on the U.S. housing market. We show that the pandemic reduced the demand for housing in neighborhoods with higher population density. We further show that the decreased demand for density is partially driven by the diminished need for living near teleworkcompatible jobs owing to the increasing prevalence of telework due to the pandemic. The decreased demand for density is also partially driven by the dwindling attraction of consumption amenities (e.g.,

\footnotetext{
${ }^{24}$ We weight observations by MSA population.
} 
restaurants), thanks to the need for social distancing. We also show that cities and neighborhoods with higher pre-COVID-19 house prices see a greater drop in housing demand.

Importantly, the effect that we find is not driven by the sudden lock-down effect of during the onset of the pandemic. As we progressed in the pandemic, the reduced demand for density in fact strengthened, implying that the results of the study is not a mechanical effect of the immediate fallout of the lockdown.

The study's findings suggest that in the wake of the sudden outbreak and continuing spread of COVID-19, contagious diseases emerge as an important dispersion force in the urban spatial equilibrium, certainly in the short run. Whether the shift away from density and central locations would last remains to be seen. As the pandemic ends and people go back to consumption amenities, traffic to and demand for dense urban centers will likely recover. The long-term effect of the pandemic may depend on the fraction of workers who opt to work from home permanently. 


\section{References}

Ahlfeldt, G., Redding, S., Sturm, D., and Wolf, N. (2015). The economics of density: Evidence from the Berlin wall. Econometrica, 83(6):2127-2189. DOI: https://doi.org/10.3982/ECTA10876.

Alexander, D. and Karger, E. (2020). Do stay-at-home orders cause people to stay at home? Effects of stay-at-home orders on consumer behavior. Federal Reserve Bank of Chicago Working Paper No. 2020-12, 20(138):138. DOI: https://doi.org/10.21033/wp-2020-12.

Allcott, H., Boxell, L., Conway, J., Ferguson, B., Gentzkow, M., and Goldman, B. (2020). Economic and health impacts of social distancing policies during the Coronavirus pandemic. Working Paper. DOI: https://dx.doi.org/10.2139/ssrn.3610422.

Atkinson, T., Dolmas, J., Koch, C., Koenig, E., Mertens, K., Murphy, A., and Yi, K.-M. (2020). Mobility and engagement following the SARS-Cov-2 outbreak. Working Paper. DOI: https: //doi.org/10.24149/wp2014.

Autor, D. and Reynolds, E. (2020). The nature of work after the COVID crisis: Too few low-wage jobs.

Bartik, A., Cullen, Z., Glaeser, E., Luca, M., and Stanton, C. (2020). What jobs are being done at home during the COVID-19 crisis? Evidence from firm-level surveys. Harvard Business School Working Paper, 20:138. DOI: https://dx.doi.org/10.2139/ssrn.3574741.

Bick, A., Blandin, A., and Mertens, K. (2020). Work from home after the COVID-19 outbreak. Federal Reserve Bank of Dallas Working Paper No. 2017. DOI: https://doi.org/10.24149/ wp2017.

Brueckner, J. (2011). Lecture on Urban Economics. MIT Press.

Chen, H., Qian, W., and Wen, Q. (2020). The impact of the COVID-19 pandemic on consumption: Learning from high frequency transaction data. Working paper. DOI: https://dx.doi.org/10. $2139 /$ ssrn.3568574.

Chetty, R., Friedman, J., Hendren, N., Stepner, M., and the Opportunity Insights Team (2020). How did COVID-19 and stabilization policies affect spending and employment? A new real-time economic tracker based on private sector data. Working Paper. DOI: https://doi.org/10.3386/ w27431.

Cox, N., Ganong, P., Noel, P., Vavra, J., Wong, A., Farrell, D., and Greig, F. (2020). Initial impacts of the pandemic on consumer behavior: Evidence from linked income, spending, and savings data. Brookings Papers on Economic Activity, Conference Draft.

Dingel, J. and Neiman, B. (2020). How many jobs can be done at home? Journal of Public Economics, 189. DOI: https://doi.org/10.1016/j.jpubeco.2020.104235.

Glaeser, E. (2011). Triumph of the city: How our greatest invention makes us richer, smarter, greener, healthier, and happier. New York: Penguin Press.

Glaeser, E. and Gottlieb, J. (2009). The wealth of cities: Agglomeration economies and spatial equilibrium in the united states. Journal of Economic Literature, 47(4):983-1028.

Glaeser, E., Kolko, J., and Saiz, A. (2000). Consumer city. Journal of Economic Geography, 1(1):2750. DOI: https://doi.org/10.1093/jeg/1.1.27. 
Holian, M. and Kahn, M. (2015). Household carbon emissions from driving and center city quality of life. Ecological Economics, 116:362-368. DOI: https://doi.org/10.1016/j.ecolecon.2015. 05.012 .

Kurmann, A., Lale, E., and Ta, L. a. (2020). The impact of COVID-19 on small business employment and hours: Real-time estimates with homebase data. Working Paper.

Manson, S., Schroeder, J., Van Riper, D., and Ruggles, S. (2020). IPUMS National Historical Geographic Information System: Version 14.0 [Database]. Minneapolis, MN: IPUMS. 2019. DOI: http://doi.org/10.18128/D050.V14.0.

Mas, A. and Pallais, A. (2020). Alternative work arrangements. Annual Review of Economics. Forthcoming. DOI: http://doi.org/10.1257/aer.20161500.

Ruggles, S., Flood, S., Goeken, R., Grover, J., Meyer, E., Pacas, J., and Sobek, M. (2020). IPUMS USA: Version 10.0 [dataset]. Minneapolis, MN: IPUMS, 2020. DOI: https://doi.org/10.18128/ D010.V10.0.

$\mathrm{Su}$, Y. (2020). Working from home during a pandemic: It's not for everyone. https://www.dallasfed.org/research/economics/2020/040\%. 


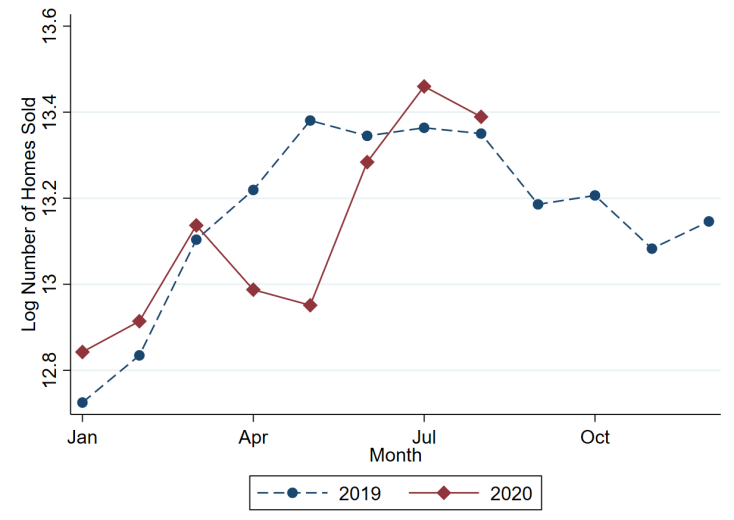

(a) Log Number of Homes Sold

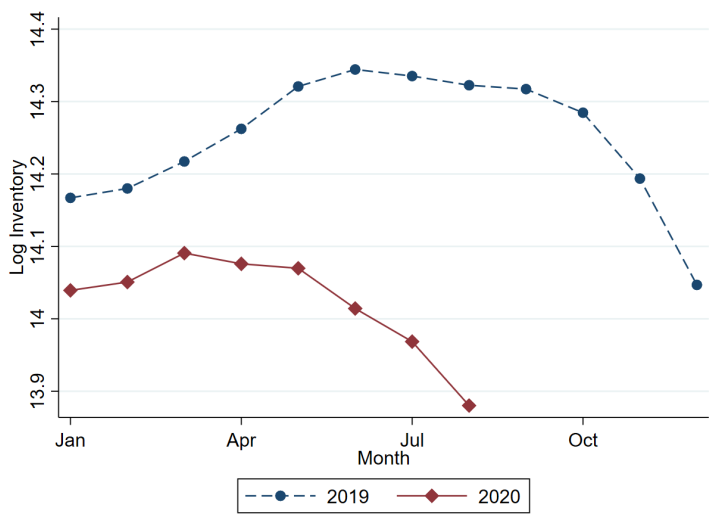

(c) Log Inventory

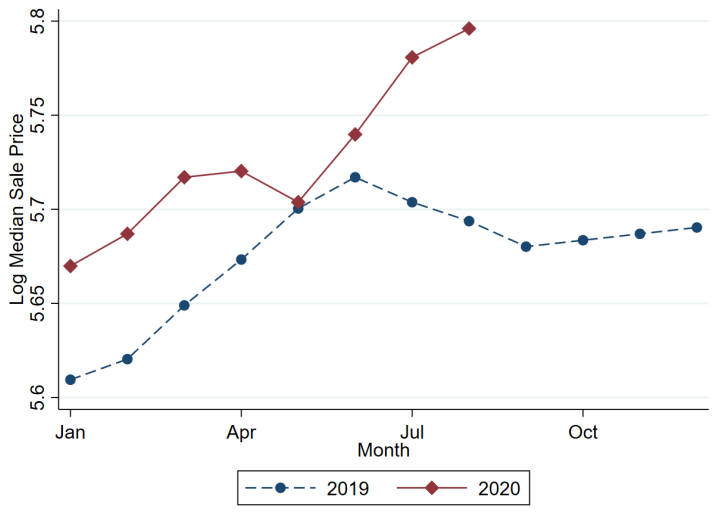

(e) Log Median Sale Price

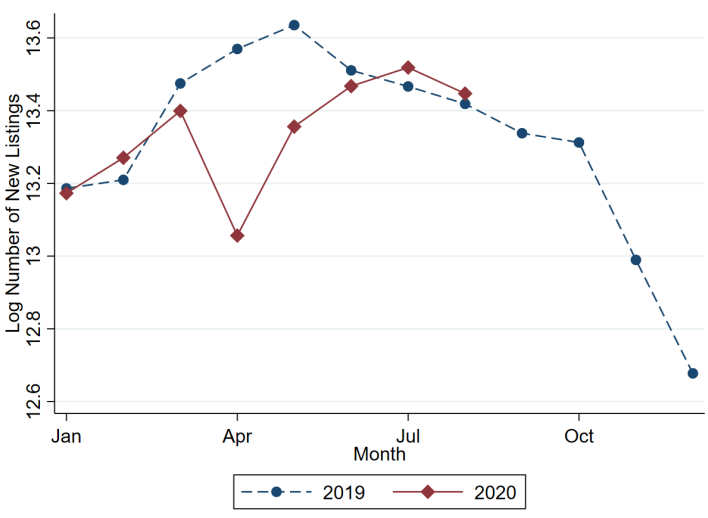

(b) Log Number of New Listings

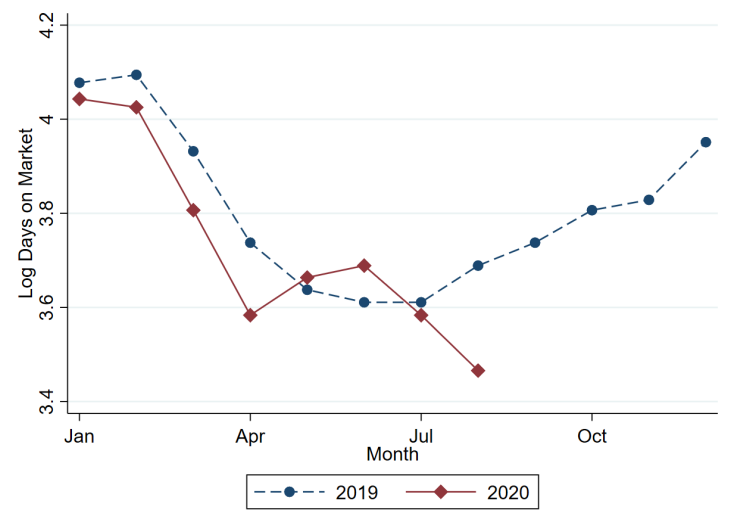

(d) Log Number of Days on Market

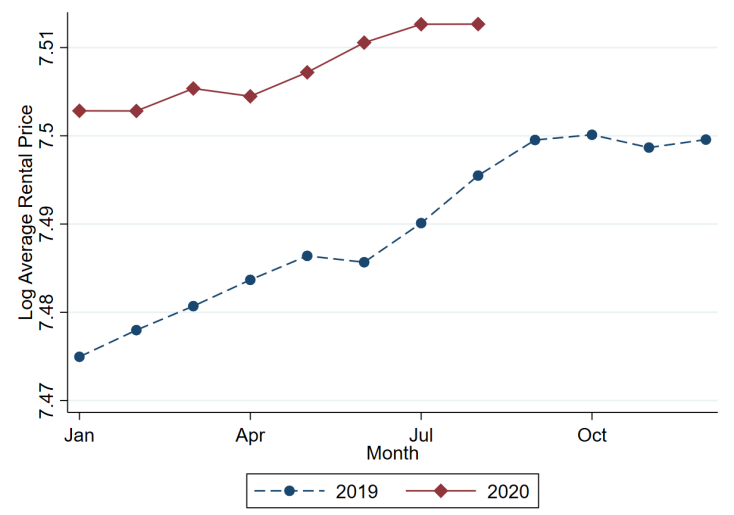

(f) Log Average Rental Price

Figure 1: Changes in the Housing Market: 2019 vs. 2020

Note: The figures present the national housing market outcomes by month for 2019 and 2020. Panels a, b, c, d, and e use national monthly data on home sales, new listings, inventory, days on market, and median sale price from Redfin Data Center. Panel f uses monthly rental price data from Zillow Research at the ZIP code level. We use the national average rents, weighted by ZIP code population. 


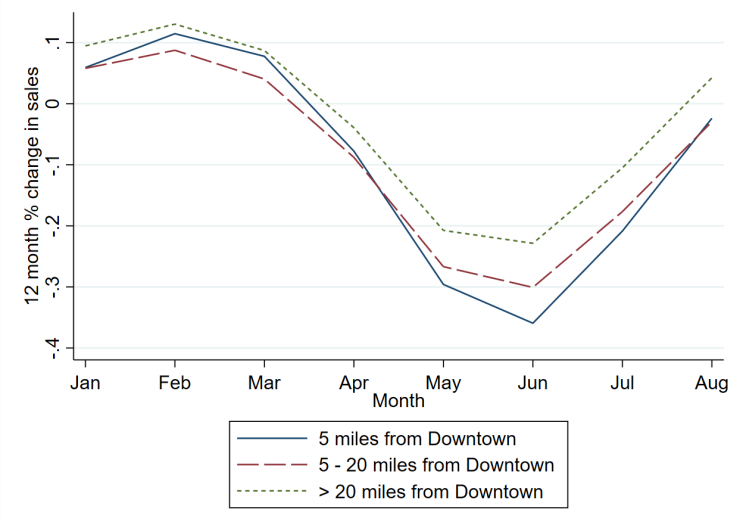

(a) Number of Homes Sold

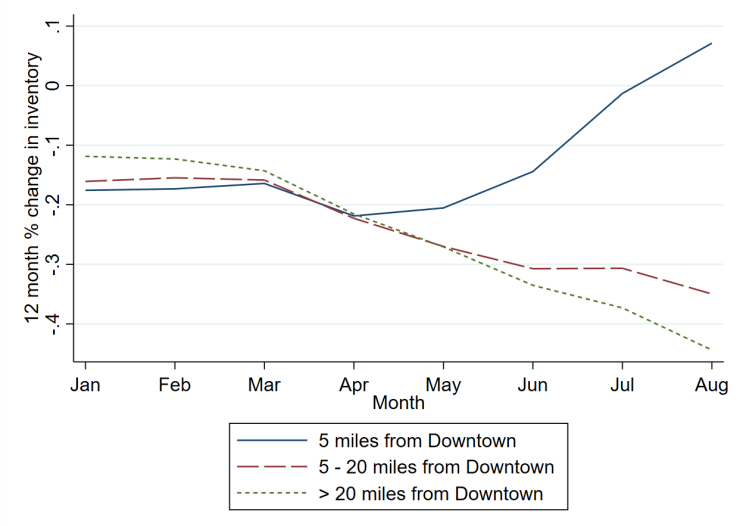

(c) Inventory

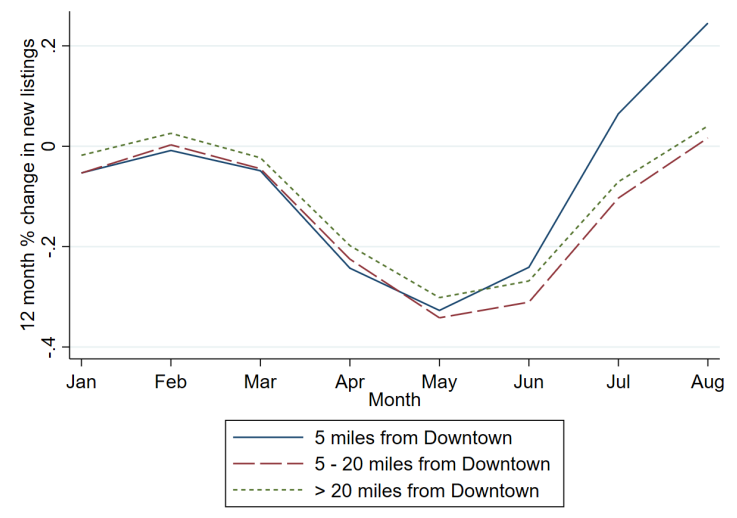

(b) Number of New Listings

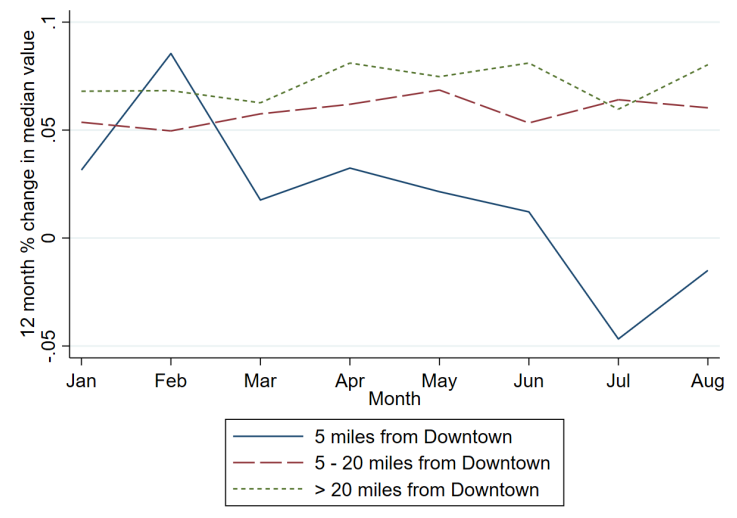

(d) Median Home Value

Figure 2: 12-month Growth Rate of Housing Market Outcomes: by Distance to Downtown

Note: The figures plot the 12-month growth rates of sales, new listings, inventory, and median home value for each month in 2020. Each number represents the growth rate from the designated month in 2019 to the same month in 2020. The sample shown includes Zip Codes in the most populous 25 MSAs in the US. The solid curve represents sample located within 5 miles of downtown of the MSA. The long dash curve represents sample located between 5 to 20 miles of downtown. The short dash curve represents sample located greater than 20 miles from downtown. 


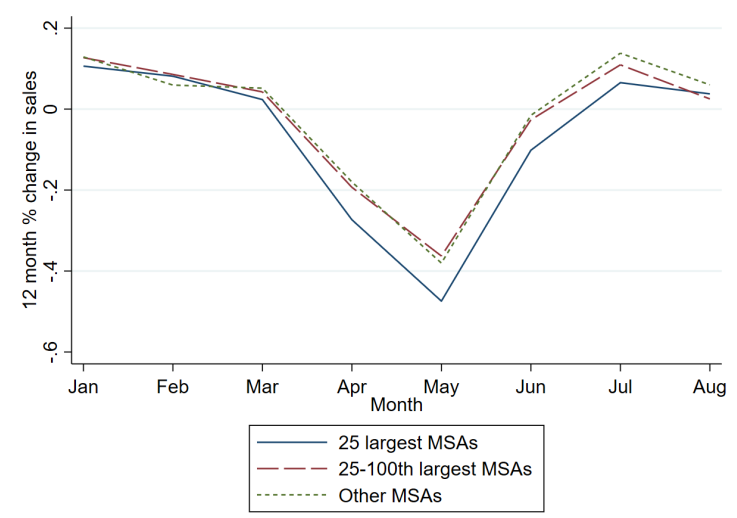

(a) Number of Homes Sold

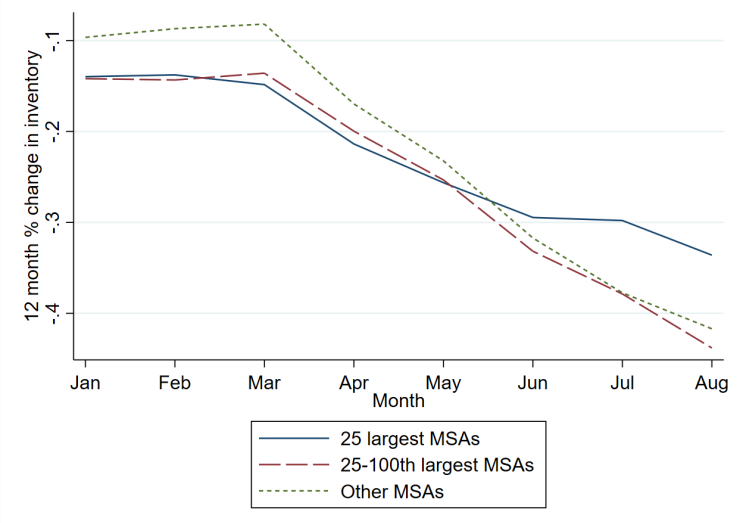

(c) Inventory

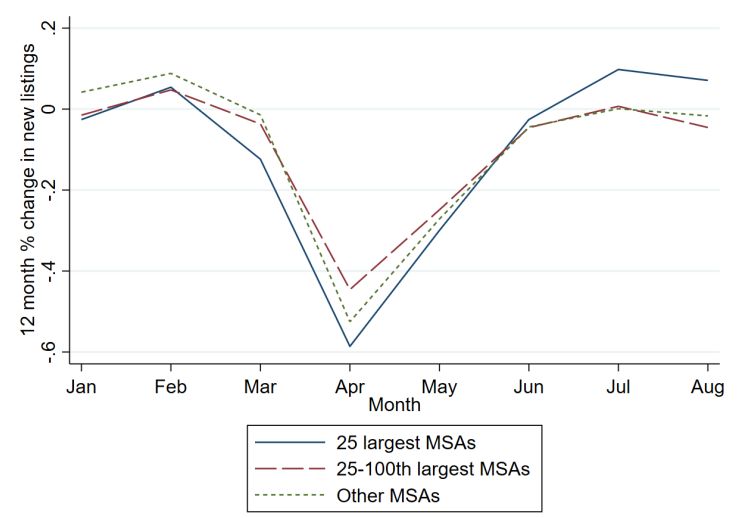

(b) Number of New Listings

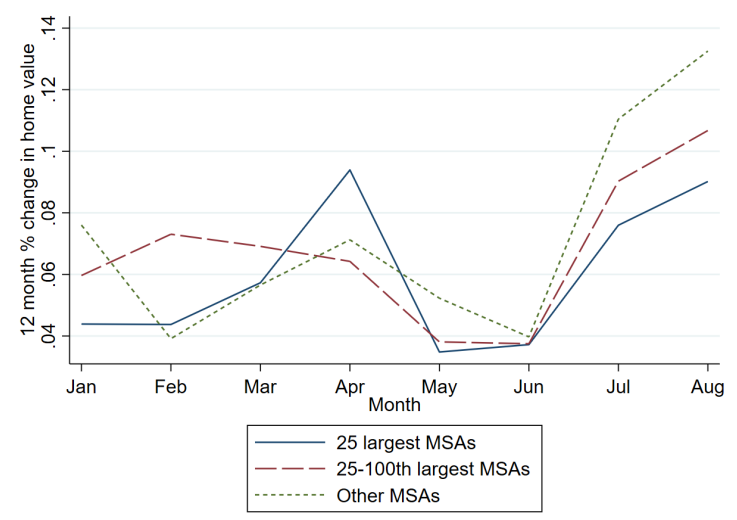

(d) Median Home Value

Figure 3: 12-month Growth Rate of Housing Market Outcomes: by MSA size

Note: The figures plot the 12-month growth rates of sales, new listings, inventory, and median home value for each month in 2020. Each number represents the growth rate from the designated month in 2019 to the same month in 2020. The sample shown includes Zip Codes in metropolitan areas in the US. The solid curve represents sample in the largest 25 MSAs. The long dash curve represents sample located between the largest 26th and 100th largest MSAs. The short dash curve represents sample located in other MSAs. 


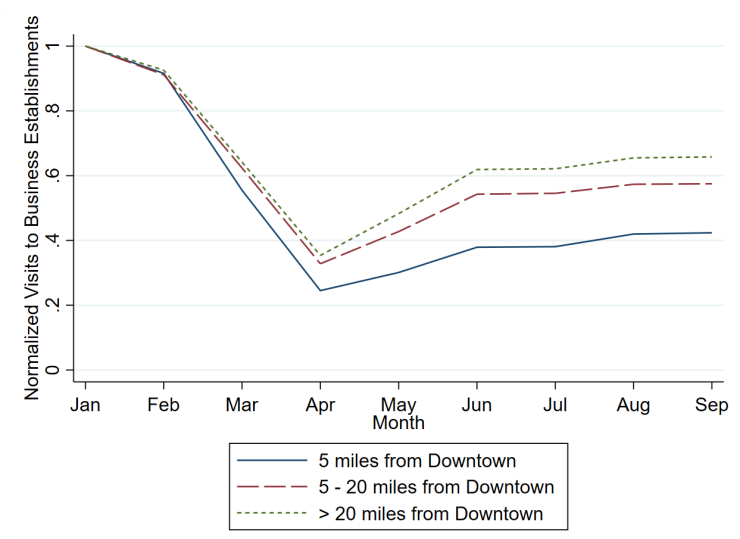

(a) Overall

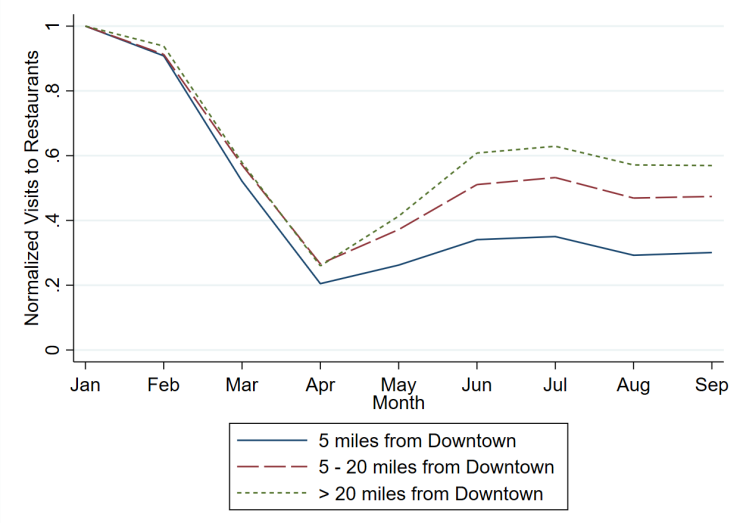

(c) Restaurant

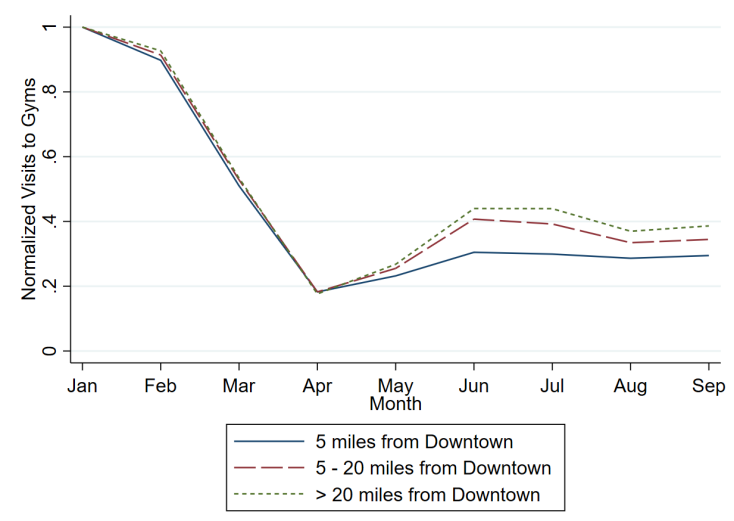

(e) Gym

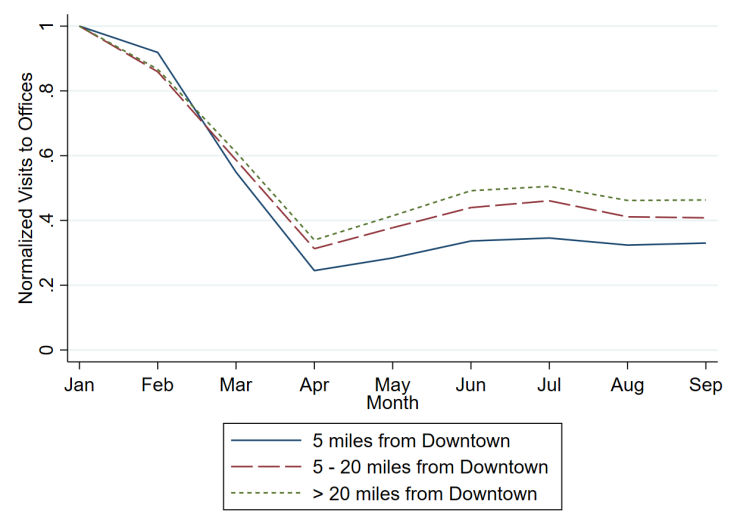

(b) Office

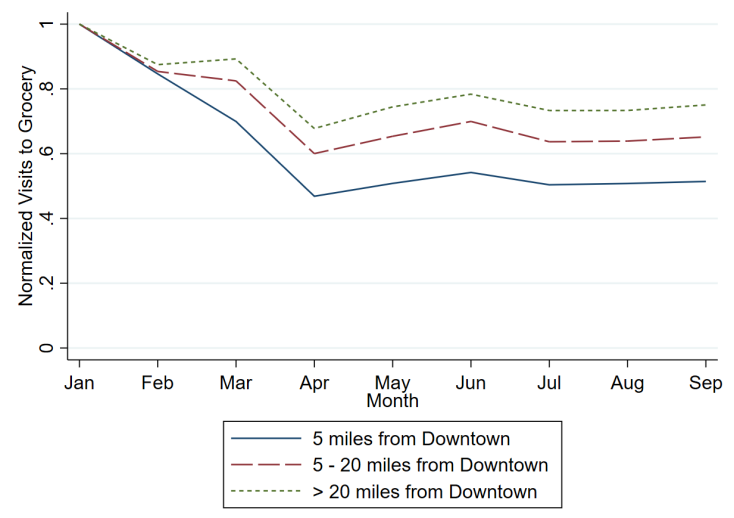

(d) Grocery Store

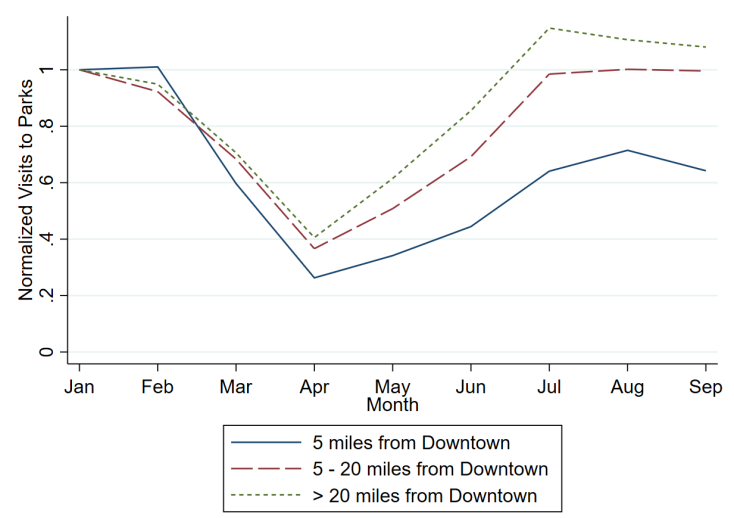

(f) Park

Figure 4: Visitor traffic to Point-of-Interest by Type and by Distance to Downtown

Note: These figures plot the average number to business establishments located within 5 miles from downtown, 5 - 20 miles from downtown, and more than 20 miles from downtown, in each month of 2020 until September, normalized by the number of visits in January 2020. Office establishments are defined as NAICS industry code 51 (Information), 52 (Finance and Insurance), 54 (Professional, Scientific, and Technical Services) 
Table 1: Heterogeneous Effects of the COVID-19 Pandemic across Counties

\begin{tabular}{|c|c|c|c|c|}
\hline & $\begin{array}{l}\log (\text { Sales }) \\
\quad(1)\end{array}$ & $\begin{array}{c}\text { Log (New Listings) } \\
(2)\end{array}$ & $\begin{array}{c}\log \text { (Inventory) } \\
(3)\end{array}$ & $\begin{array}{c}\log \text { (Price) } \\
(4)\end{array}$ \\
\hline \multicolumn{5}{|l|}{ Panel A: Average Effects } \\
\hline After $\times \log ($ Density $)$ & $\begin{array}{c}-0.0189^{* * *} \\
(0.00426)\end{array}$ & $\begin{array}{l}0.0143^{* *} \\
(0.00621)\end{array}$ & $\begin{array}{c}0.0296^{* * *} \\
(0.00630)\end{array}$ & $\begin{array}{c}0.00257 \\
(0.00419)\end{array}$ \\
\hline After $\times$ Log $($ Pre-COVID Price $)$ & $\begin{array}{c}-0.171^{* * *} \\
(0.0169)\end{array}$ & $\begin{array}{c}0.0868^{* * * *} \\
(0.0247)\end{array}$ & $\begin{array}{c}0.241^{* * *} \\
(0.0247)\end{array}$ & $\begin{array}{c}0.0260 \\
(0.0217)\end{array}$ \\
\hline Observations & 65,184 & 65,184 & 65,184 & 63,110 \\
\hline \multicolumn{5}{|l|}{ Panel B: Effects by Months } \\
\hline April $\times \log ($ Density $)$ & $\begin{array}{l}-0.0185^{* *} \\
(0.00878)\end{array}$ & $\begin{array}{l}-0.0164^{*} \\
(0.00878)\end{array}$ & $\begin{array}{c}0.00488 \\
(0.00459)\end{array}$ & $\begin{array}{c}0.0158 \\
(0.00997)\end{array}$ \\
\hline May × Log (Density) & $\begin{array}{c}-0.0288^{* * *} \\
(0.00874)\end{array}$ & $\begin{array}{l}-0.00879 \\
(0.00662)\end{array}$ & $\begin{array}{l}0.00927^{*} \\
(0.00509)\end{array}$ & $\begin{array}{l}-0.00563 \\
(0.00432)\end{array}$ \\
\hline June $\times \log ($ Density $)$ & $\begin{array}{c}-0.0215^{* * *} \\
(0.00579)\end{array}$ & $\begin{array}{c}0.0120^{*} \\
(0.00626)\end{array}$ & $\begin{array}{l}0.0239^{* * *} \\
(0.00642)\end{array}$ & $\begin{array}{c}0.00378 \\
(0.00469)\end{array}$ \\
\hline July × Log (Density) & $\begin{array}{l}-0.0156^{* *} \\
(0.00697)\end{array}$ & $\begin{array}{c}0.0461^{* * *} \\
(0.0105)\end{array}$ & $\begin{array}{l}0.0497^{* * *} \\
(0.00870)\end{array}$ & $\begin{array}{l}-0.000165 \\
(0.00509)\end{array}$ \\
\hline August $\times \log$ (Density) & $\begin{array}{l}-0.0102 \\
(0.0117)\end{array}$ & $\begin{array}{c}0.0386^{* * *} \\
(0.0110)\end{array}$ & $\begin{array}{c}0.0603^{* * *} \\
(0.0122)\end{array}$ & $\begin{array}{l}-0.000871 \\
(0.00437)\end{array}$ \\
\hline April $\times$ Log (Pre-COVID Price $)$ & $\begin{array}{c}-0.0865^{* *} \\
(0.0393)\end{array}$ & $\begin{array}{c}-0.345^{* * *} \\
(0.0720)\end{array}$ & $\begin{array}{c}0.0429 \\
(0.0295)\end{array}$ & $\begin{array}{c}0.129^{*} \\
(0.0704)\end{array}$ \\
\hline May × Log (Pre-COVID Price) & $\begin{array}{l}-0.0751 \\
(0.0950)\end{array}$ & $\begin{array}{c}-0.107 \\
(0.0827)\end{array}$ & $\begin{array}{c}0.0910^{* * *} \\
(0.0169)\end{array}$ & $\begin{array}{l}0.0348^{*} \\
(0.0204)\end{array}$ \\
\hline June $\times$ Log (Pre-COVID Price) & $\begin{array}{l}-0.0743 \\
(0.0518)\end{array}$ & $\begin{array}{l}0.155^{* * *} \\
(0.0364)\end{array}$ & $\begin{array}{l}0.237^{* * *} \\
(0.0305)\end{array}$ & $\begin{array}{l}0.00654 \\
(0.0194)\end{array}$ \\
\hline July $\times$ Log (Pre-COVID Price) & $\begin{array}{c}-0.245^{* * *} \\
(0.0881)\end{array}$ & $\begin{array}{c}0.365^{* * *} \\
(0.0450)\end{array}$ & $\begin{array}{l}0.352^{* * *} \\
(0.0385)\end{array}$ & $\begin{array}{c}0.0178 \\
(0.0199)\end{array}$ \\
\hline August $\times$ Log (Pre-COVID Price) & $\begin{array}{c}-0.372^{* * *} \\
(0.140)\end{array}$ & $\begin{array}{l}0.366^{* * *} \\
(0.0452)\end{array}$ & $\begin{array}{l}0.483^{* * *} \\
(0.0670)\end{array}$ & $\begin{array}{c}-0.0573^{* * *} \\
(0.0211)\end{array}$ \\
\hline Observations & 63,774 & 63,774 & 63,774 & 61,711 \\
\hline
\end{tabular}

Note: The sample comprises all counties between January 2016 and August 2020. The dependent variable includes log number of homes sold, log new listings, log inventory, and log median house sale price. In Panel A, After is a dummy variable that is equal to 1 if the observation is between April and August 2020, and 0 otherwise. In Panel B, the month dummies are indicators of the corresponding month of 2020. All specifications in Panel A include year $\times$ month, After $\times$ MSA, county $\times$ year, and county $\times$ month fixed effects, After $\times \log$ income level, After $\times$ fraction of whites, and After $\times \log$ average case rate. (After is replaced with post-COVID month dummies in Panel B.) Observations are weighted by the county's population. Standard errors are clustered at the MSA level: ${ }^{* * *} p<0.01,{ }^{* *} p<0.05,{ }^{*} p<0.1$. 
Table 2: Heterogeneous Effects of the COVID-19 Pandemic across ZIP Codes

Log (Sales) Log (New Listings) Log (Inventory) Log (Price) $\quad$ Log (Rent)

$(1)$

(2)

(3)

(4)

(5)

\section{Panel A: Baseline}

After $\times \log \left(\right.$ Distance to Downtown) $\quad 0.0239 * * * \quad-0.0173^{*} \quad-0.0638^{* * *} \quad 0.00183 \quad 0.0278^{* * *}$

$\begin{array}{lllll}(0.00406) & (0.00913) & (0.00896) \quad(0.00431) & (0.000588)\end{array}$

After $\times \log ($ Density $) \quad-0.0246^{* * *} \quad-0.00744 \quad 0.0192^{* * *} \quad-0.00352^{* *} \quad-0.00257^{* * *}$

$\begin{array}{llll}(0.00619) \quad(0.00864) & (0.00592) \quad(0.00171) \quad(0.000515)\end{array}$

\begin{tabular}{lccccc} 
Observations & 577,555 & 577,555 & 577,555 & 539,276 & 163,581 \\
\hline & Log (Sales) & Log (New Listings) & Log (Inventory) & Log (Price) & Log (Rent)
\end{tabular}

(1)

(2)

(4)

\section{Panel B: Job and Amenity}

\begin{tabular}{|c|c|c|c|c|c|}
\hline \multirow[t]{2}{*}{ After $\times \log ($ Distance to Downtown $)$} & $0.0150^{* * *}$ & -0.00278 & $-0.0303^{* * *}$ & 0.00227 & $0.000891^{*}$ \\
\hline & $(0.00445)$ & $(0.00811)$ & $(0.00671)$ & $(0.00428)$ & $(0.000532)$ \\
\hline \multirow[t]{2}{*}{ After $\times$ Log (Density) } & $-0.0207^{* * *}$ & $-0.0159^{*}$ & 0.00226 & $-0.00350^{* *}$ & $-0.00171^{* * *}$ \\
\hline & $(0.00599)$ & $(0.00897)$ & $(0.00574)$ & $(0.00159)$ & $(0.000448)$ \\
\hline \multirow[t]{2}{*}{ After $\times$ Log $($ Jobs per capita $)$} & 0.00801 & 0.00572 & 0.00357 & -0.000558 & -0.00106 \\
\hline & $(0.00576)$ & $(0.00730)$ & $(0.0103)$ & $(0.00456)$ & $(0.000667)$ \\
\hline After $\times$ Log (Share of Telework Jobs) & $-0.0635^{* * *}$ & $0.0366^{*}$ & $0.118^{* * *}$ & 0.00938 & $-0.00772^{* * *}$ \\
\hline
\end{tabular}




\begin{tabular}{|c|c|c|c|c|c|}
\hline & $(0.0139)$ & $(0.0202)$ & $(0.0208)$ & $(0.00803)$ & $(0.00153)$ \\
\hline \multirow[t]{2}{*}{ After $\times \log ($ Restaurants per capita) } & $-0.0164^{* * *}$ & $0.0173^{* *}$ & $0.0442^{* * *}$ & 0.000171 & -0.000862 \\
\hline & $(0.00616)$ & $(0.00753)$ & $(0.0105)$ & $(0.00502)$ & $(0.000618)$ \\
\hline \multirow[t]{3}{*}{ Observations } & 544,390 & 544,390 & 544,390 & 517,048 & 163,321 \\
\hline & Log (Sales) & Log (New Listings) & Log (Inventory) & Log (Price) & Log (Rent) \\
\hline & $(1)$ & $(2)$ & $(3)$ & $(4)$ & $(5)$ \\
\hline \multicolumn{6}{|c|}{ Panel C: Socioeconomic Characteristics and Racial Composition } \\
\hline \multirow[t]{2}{*}{ After $\times \log ($ Distance to Downtown $)$} & $0.0191^{* * *}$ & $-0.0231^{* * *}$ & $-0.0507^{* * *}$ & -0.000668 & $0.00174^{* * *}$ \\
\hline & $(0.00430)$ & $(0.00883)$ & $(0.00797)$ & $(0.00477)$ & $(0.000495)$ \\
\hline \multirow[t]{2}{*}{ After $\times$ Log (Density) } & $-0.0237^{* * *}$ & 0.000383 & $0.0170^{* * *}$ & -0.00115 & $-0.00228^{* * *}$ \\
\hline & $(0.00479)$ & $(0.00623)$ & $(0.00577)$ & $(0.00190)$ & $(0.000346)$ \\
\hline \multirow[t]{2}{*}{ After $\times$ Log (Pre-COVID Price $)$} & $-0.0600^{* * *}$ & 0.0261 & $0.139^{* * *}$ & -0.00310 & $-0.00825^{* * *}$ \\
\hline & $(0.00714)$ & $(0.0270)$ & $(0.0257)$ & $(0.00699)$ & $(0.000881)$ \\
\hline \multirow[t]{2}{*}{ After $\times \log ($ Income $)$} & $0.0251^{* *}$ & 0.0366 & $-0.128^{* * *}$ & $0.0208^{* *}$ & $0.00491^{* * *}$ \\
\hline & $(0.0117)$ & $(0.0304)$ & $(0.0337)$ & $(0.00905)$ & $(0.00133)$ \\
\hline \multirow[t]{2}{*}{ After ${ }^{*} \log ($ Share of Whites) } & -0.000339 & $0.0335^{* * *}$ & $0.0339^{* * *}$ & 0.00524 & $-0.00135^{* * *}$ \\
\hline & $(0.00434)$ & $(0.00625)$ & $(0.00735)$ & $(0.00339)$ & $(0.000415)$ \\
\hline Observations & 555,005 & 555,005 & 555,005 & 535,664 & 162,378 \\
\hline
\end{tabular}


Log (Sales) Log (New Listings) Log (Inventory) Log (Price) Log (Rent)
(1)
(2)
(3)
(4)
(5)

\section{Panel D: All}

After $\times \log ($ Distance to Downtown)

$0.0135^{* * *} \quad-0.0155^{* *}$

$-0.0274^{* * *}$

$-0.00133 \quad 0.000686$

After $\times \log ($ Density $)$

$(0.00439) \quad(0.00784)$

$(0.00658)$

$(0.00498) \quad(0.000462)$

After $\times$ Log (Density)

$-0.0212^{* * *} \quad-0.00392$

$0.00476 \quad-0.000259-0.00195^{* * *}$

(0.00528) (0.00696)

(0.00550)

$(0.00201) \quad(0.000341)$

After $\times$ Log (Jobs per capita)

$0.00291 \quad 0.0183^{* *}$

0.0152

$0.00214-0.00213^{* * *}$

$(0.00574) \quad(0.00717)$

(0.00922)

$(0.00471) \quad(0.000675)$

After $\times \log ($ Share of Telework Jobs)

$-0.0427 * * *$

$-0.00839$

$0.0837^{* * *}$

$-0.000309-0.00500^{* * *}$

$(0.0145) \quad(0.0263)$

(0.0202)

$(0.00834) \quad(0.00127)$

After $\times$ Log (Restaurants per capita)

$-0.00819 \quad-0.00288$

$0.0196^{* *}$

$-0.00369$

$0.00117^{*}$

(0.00577) (0.00682)

(0.00954)

(0.00577)

$(0.000626)$

After $\times \log ($ Pre-COVID Price)

$-0.0524^{* * *}$

0.0193

$0.113^{* * *}$

$-0.00281$

$-0.00712^{* * *}$

(0.00752)

(0.0272)

After $\times \log ($ Income $)$

$0.0214^{*}$

0.0442

(0.0113)

(0.0285)

After $\times$ Log (Share of Whites)

$\begin{array}{ll}0.00147 & 0.0301^{* * *} \\ (0.00458) & (0.00621)\end{array}$

(0.0218)

$(0.00737) \quad(0.000816)$

$\begin{array}{lll}-0.108^{* * *} & 0.0202^{* *} & 0.00453^{* * *}\end{array}$

$(0.0240) \quad(0.00890) \quad(0.00119)$

$0.0239^{* * *} \quad 0.00594^{*}-0.00105^{* *}$

$(0.00603) \quad(0.00359) \quad(0.000420)$ 
Note: The sample comprises all ZIP Codes between January 2016 and August 2020, except April 2020. The dependent variable includes log number of homes sold, log new listings, log inventory, log median house sale price, and log rental price. After is a dummy variable that is equal to 1 if the observation is between May and August 2020, and 0 otherwise. All specifications include year $\times$ month, MSA $\times$ After, ZIP code $\times$ year, and ZIP code $\times$ month fixed effects, and After $\times \log$ average case rate. Observations are weighted by the ZIP code's population Standard errors are clustered at the MSA level: ${ }^{* * *} p<0.01,{ }^{* *} p<0.05,{ }^{*} p<0.1$. 
Table 3: Heterogeneous Effects of the COVID-19 Pandemic across ZIP Codes: Effects by Month

\begin{tabular}{|c|c|c|c|c|c|}
\hline & $\begin{array}{c}\text { Log (Sales) } \\
(1)\end{array}$ & $\begin{array}{c}\text { Log (New Listings) } \\
(2)\end{array}$ & $\begin{array}{c}\text { Log (Inventory) } \\
(3)\end{array}$ & $\begin{array}{c}\log (\text { Price }) \\
(4)\end{array}$ & $\begin{array}{c}\log (\text { Rent }) \\
(5)\end{array}$ \\
\hline \multirow[t]{2}{*}{ May-Jun $\times$ Log (Distance to Downtown) } & $0.00992^{*}$ & -0.00348 & -0.00371 & -0.00224 & 0.000543 \\
\hline & $(0.00556)$ & $(0.00606)$ & $(0.00595)$ & $(0.00460)$ & $(0.000371)$ \\
\hline \multirow[t]{2}{*}{ Jul-Aug $\times$ Log (Distance to Downtown) } & $0.0171^{* * *}$ & $-0.0276^{* *}$ & $-0.0510^{* * *}$ & -0.000468 & 0.000844 \\
\hline & $(0.00461)$ & $(0.0107)$ & $(0.0100)$ & $(0.00559)$ & $(0.000554)$ \\
\hline \multirow[t]{2}{*}{ May-Jun × Log (Density) } & $-0.0185^{* * *}$ & -0.00758 & 0.00617 & 0.00171 & $-0.00148^{* * *}$ \\
\hline & $(0.00433)$ & $(0.00964)$ & $(0.00516)$ & $(0.00263)$ & $(0.000260)$ \\
\hline \multirow[t]{2}{*}{ Jul-Aug × Log (Density) } & $-0.0240^{* * *}$ & -0.000259 & 0.00335 & -0.00227 & $-0.00239^{* * *}$ \\
\hline & $(0.00705)$ & $(0.00490)$ & $(0.00655)$ & $(0.00197)$ & $(0.000423)$ \\
\hline \multirow[t]{2}{*}{ May-Jun × Log (Jobs per capita) } & $0.0121^{*}$ & $0.0199^{* * *}$ & $0.0196^{* * *}$ & 0.00434 & $-0.00151^{* * *}$ \\
\hline & $(0.00689)$ & $(0.00694)$ & $(0.00684)$ & $(0.00475)$ & $(0.000507)$ \\
\hline \multirow[t]{2}{*}{ Jul-Aug $\times$ Log (Jobs per capita) } & -0.00627 & $0.0167^{* *}$ & 0.0107 & $-9.28 \mathrm{e}-05$ & $-0.00275^{* * *}$ \\
\hline & $(0.00907)$ & $(0.00843)$ & $(0.0132)$ & $(0.00513)$ & $(0.000854)$ \\
\hline \multirow[t]{2}{*}{ May-Jun $\times$ Log (Share of Telework Jobs) } & $-0.0673^{* * *}$ & -0.0344 & $0.0432^{* * *}$ & -0.000367 & $-0.00409^{* * *}$ \\
\hline & $(0.0148)$ & $(0.0327)$ & $(0.0141)$ & $(0.00791)$ & $(0.00103)$ \\
\hline \multirow[t]{2}{*}{ Jul-Aug $\times \log ($ Share of Telework Jobs $)$} & -0.0181 & 0.0176 & $0.124^{* * *}$ & -0.000117 & $-0.00591^{* * *}$ \\
\hline & $(0.0181)$ & $(0.0225)$ & $(0.0303)$ & $(0.00972)$ & $(0.00154)$ \\
\hline \multirow[t]{2}{*}{ May-Jun $\times$ Log (Restaurants per capita) } & $-0.0191^{* * *}$ & -0.0117 & -0.00163 & -0.00640 & 0.000802 \\
\hline & $(0.00576)$ & $(0.00749)$ & $(0.00781)$ & $(0.00586)$ & $(0.000505)$ \\
\hline
\end{tabular}




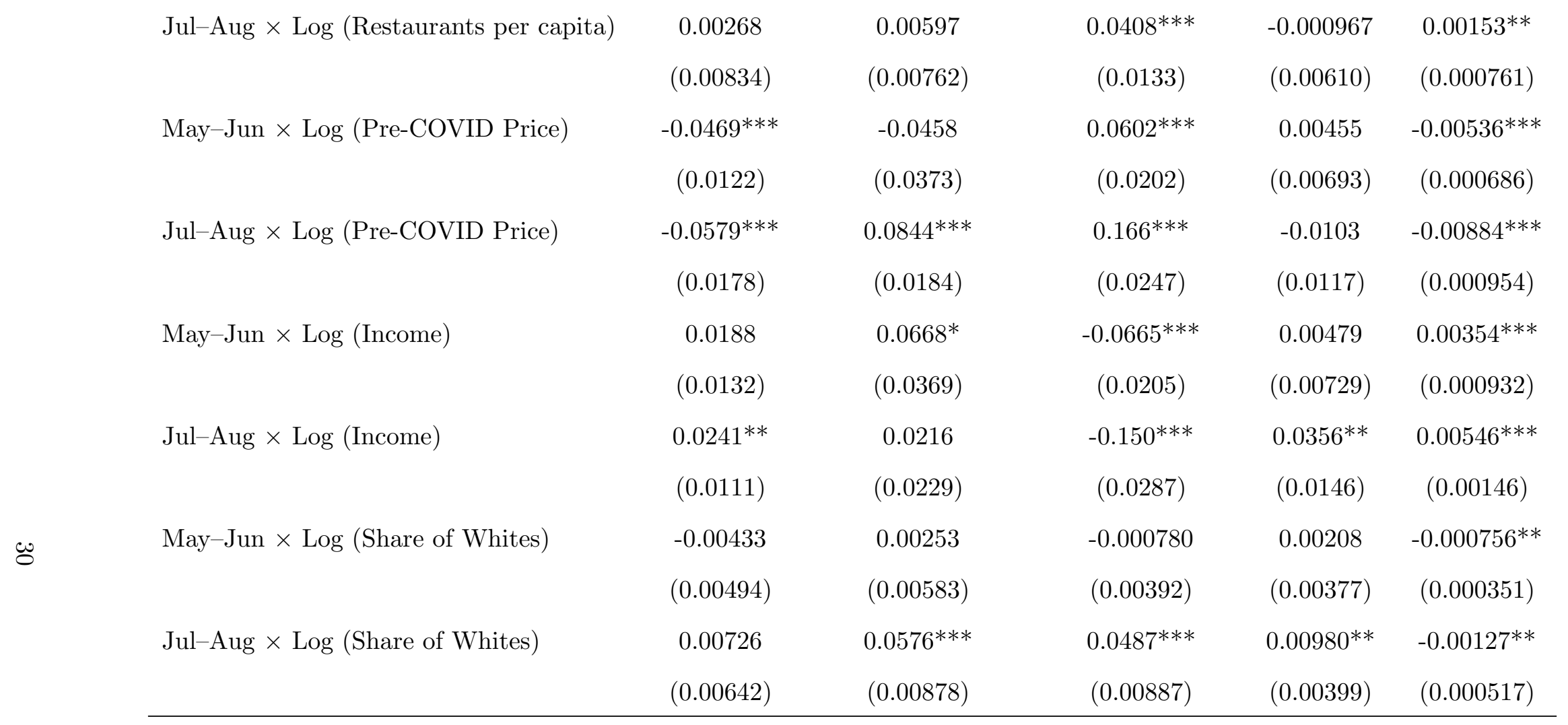

Note: The sample comprises all ZIP Codes between January 2016 and August 2020, except April 2020. The dependent variable includes $\log$ number of homes sold, log new listings, log inventory, log median house sale price, and log rental price. May-Jun is a dummy variable that is equal to 1 if the observation is between May and June 2020, and 0 otherwise. Jul-Aug is a dummy variable that is equal to 1 if the observation is between July and August 2020, and 0 otherwise. All specifications include year $\times$ month, MSA $\times$ post-COVID month dummies, ZIP code $\times$ year, and ZIP code $\times$ month fixed effects, and post-COVID month dummies $\times$ log average case rate. Observations are weighted by the ZIP code's population. Standard errors are clustered at the MSA level: ${ }^{* * *} p<0.01,{ }^{* *} p<0.05,{ }^{*} p<0.1$. 
Table 4: Heterogeneous Effects of the COVID-19 Pandemic Across Metropolitan Areas

\begin{tabular}{|c|c|c|c|c|c|}
\hline & $\begin{array}{c}\log \text { (Sales) } \\
\text { (1) }\end{array}$ & $\begin{array}{c}\text { Log (New Listings) } \\
(2)\end{array}$ & $\begin{array}{c}\log \text { (Inventory) } \\
(3)\end{array}$ & $\begin{array}{c}\log \text { (Price) } \\
(4)\end{array}$ & $\begin{array}{c}\overline{\log (\text { Rent })} \\
(5)\end{array}$ \\
\hline After $\times \log ($ Population $)$ & $\begin{array}{c}-0.0275^{* *} \\
(0.0122)\end{array}$ & $\begin{array}{c}0.00458 \\
(0.00951)\end{array}$ & $\begin{array}{l}0.00713 \\
(0.0120)\end{array}$ & $\begin{array}{l}-0.00555^{*} \\
(0.00329)\end{array}$ & $\begin{array}{l}-0.00209 \\
(0.00136)\end{array}$ \\
\hline After $\times \log$ (Share of Teleworkers) & $\begin{array}{c}0.120 \\
(0.108)\end{array}$ & $\begin{array}{c}0.182^{*} \\
(0.0951)\end{array}$ & $\begin{array}{l}0.259^{* *} \\
(0.124)\end{array}$ & $\begin{array}{c}-0.00479 \\
(0.0245)\end{array}$ & $\begin{array}{c}0.00964 \\
(0.00983)\end{array}$ \\
\hline After $\times \log$ (Restaurants per capita) & $\begin{array}{l}-0.0347 \\
(0.0507)\end{array}$ & $\begin{array}{c}0.0187 \\
(0.0378)\end{array}$ & $\begin{array}{l}-0.0544 \\
(0.0532)\end{array}$ & $\begin{array}{l}-0.00579 \\
(0.0118)\end{array}$ & $\begin{array}{l}-0.00850^{*} \\
(0.00509)\end{array}$ \\
\hline After $\times$ Log $($ Pre-COVID Price $)$ & $\begin{array}{c}-0.104^{* * *} \\
(0.0344)\end{array}$ & $\begin{array}{c}0.0159 \\
(0.0275)\end{array}$ & $\begin{array}{l}0.163^{* * *} \\
(0.0364)\end{array}$ & $\begin{array}{c}-0.0104 \\
(0.00727)\end{array}$ & $\begin{array}{r}-0.0166^{* * *} \\
(0.00280)\end{array}$ \\
\hline After $\times \log ($ Income $)$ & $\begin{array}{c}0.125 \\
(0.0927)\end{array}$ & $\begin{array}{l}-0.112 \\
(0.0758)\end{array}$ & $\begin{array}{c}-0.323^{* * *} \\
(0.0983)\end{array}$ & $\begin{array}{c}0.0240 \\
(0.0197)\end{array}$ & $\begin{array}{c}0.0102 \\
(0.00800)\end{array}$ \\
\hline After $\times \log$ (Share of Whites) & $\begin{array}{l}-0.0303 \\
(0.0248)\end{array}$ & $\begin{array}{l}-0.0402 \\
(0.0356)\end{array}$ & $\begin{array}{c}0.0414 \\
(0.0299)\end{array}$ & $\begin{array}{l}-0.00602 \\
(0.00705)\end{array}$ & $\begin{array}{r}-0.00862^{* *} \\
(0.00359)\end{array}$ \\
\hline
\end{tabular}

Note: The sample comprises all metropolitan statistical areas (MSAs) between January 2016 and August 2020. The dependent variable includes log number of homes sold, log new listings, $\log$ median house sale price, and log rental price. After is a dummy variable that is equal to 1 if the observation is between April and August 2020, and 0 otherwise. All specifications include year $\times$ month, MSA $\times$ year, and MSA $\times$ month fixed effects, and After $\times \log$ average case rate. Observations are weighted by the MSA's population. Standard errors are clustered at the MSA level: ${ }^{* * *} p<0.01,{ }^{* *} p<0.05,{ }^{*} p<0.1$. 
Table 5: Heterogeneous Effects of the COVID-19 Pandemic across Metropolitan Areas: Effects by Month

\begin{tabular}{|c|c|c|c|c|c|}
\hline & $\begin{array}{c}\log (\text { Sales }) \\
(1)\end{array}$ & $\begin{array}{c}\text { Log (New Listings) } \\
(2)\end{array}$ & $\begin{array}{c}\log \text { (Inventory) } \\
(3)\end{array}$ & $\begin{array}{c}\log \text { (Prices) } \\
(4)\end{array}$ & $\begin{array}{c}\log \text { (Rents) } \\
(5)\end{array}$ \\
\hline \multirow[t]{2}{*}{ Apr-Jun $\times$ Log (Population) } & $-0.0368^{* *}$ & -0.0213 & -0.00388 & -0.00410 & $-0.00303^{* *}$ \\
\hline & $(0.0186)$ & $(0.0154)$ & $(0.00606)$ & $(0.00400)$ & $(0.00137)$ \\
\hline \multirow{2}{*}{ Jul-Aug × Log (Population) } & -0.0134 & $0.0434^{* *}$ & 0.0236 & $-0.00771^{*}$ & -0.000669 \\
\hline & $(0.0134)$ & $(0.0180)$ & $(0.0233)$ & $(0.00435)$ & $(0.00159)$ \\
\hline \multirow[t]{2}{*}{ Apr-Jun $\times$ Log (Share of Teleworkers) } & $0.255^{*}$ & $0.425^{* * *}$ & $0.250^{* * *}$ & -0.0288 & 0.0159 \\
\hline & $(0.151)$ & $(0.127)$ & $(0.0729)$ & $(0.0308)$ & $(0.00963)$ \\
\hline \multirow{2}{*}{ Jul-Aug $\times$ Log (Share of Teleworkers) } & -0.0830 & -0.183 & 0.273 & 0.0312 & 0.000296 \\
\hline & $(0.121)$ & $(0.149)$ & $(0.229)$ & $(0.0352)$ & $(0.0122)$ \\
\hline \multirow[t]{2}{*}{ Apr-Jun $\times$ Log (restaurants per capita) } & 0.0170 & $-0.141^{* *}$ & $-0.131^{* * *}$ & 0.00445 & $-0.00882^{*}$ \\
\hline & $(0.0750)$ & $(0.0572)$ & $(0.0280)$ & $(0.0166)$ & $(0.00514)$ \\
\hline \multirow{2}{*}{ Jul-Aug $\times$ Log (restaurants per capita) } & $-0.112^{* *}$ & $0.258^{* * *}$ & 0.0613 & -0.0213 & -0.00802 \\
\hline & $(0.0552)$ & $(0.0933)$ & $(0.113)$ & $(0.0138)$ & $(0.00608)$ \\
\hline \multirow[t]{2}{*}{ Apr--Jun $\times$ Log (Pre-COVID Price $)$} & $-0.150^{* * *}$ & 0.0332 & $0.154^{* * *}$ & -0.0156 & $-0.0134^{* * *}$ \\
\hline & $(0.0490)$ & $(0.0371)$ & $(0.0201)$ & $(0.00990)$ & $(0.00284)$ \\
\hline \multirow[t]{2}{*}{ Jul-Aug * Log (Pre-COVID Price) } & -0.0345 & -0.0101 & $0.176^{* *}$ & -0.00255 & $-0.0214^{* * *}$ \\
\hline & $(0.0366)$ & $(0.0528)$ & $(0.0678)$ & $(0.00894)$ & $(0.00335)$ \\
\hline \multirow[t]{2}{*}{ Apr-Jun6 × Log (Income) } & 0.0957 & $-0.338^{* * *}$ & $-0.328^{* * *}$ & 0.0389 & 0.00639 \\
\hline & $(0.127)$ & $(0.0922)$ & $(0.0591)$ & $(0.0253)$ & $(0.00818)$ \\
\hline
\end{tabular}




\begin{tabular}{lccccc} 
Jul-Aug $\times$ Log (Income) & $0.169^{*}$ & 0.226 & $-0.317^{*}$ & 0.00182 & $0.0159^{*}$ \\
& $(0.0975)$ & $(0.138)$ & $(0.181)$ & $(0.0285)$ & $(0.00904)$ \\
Apr-Jun $\times \log ($ Share of Whites) & -0.0369 & -0.0598 & $0.0363^{* *}$ & -0.00113 & $-0.00836^{* *}$ \\
& $(0.0370)$ & $(0.0498)$ & $(0.0171)$ & $(0.00679)$ & $(0.00354)$ \\
Jul-Aug $\times$ Log (Share of Whites) & -0.0205 & -0.0108 & 0.0492 & -0.0133 & $-0.00900^{* *}$ \\
& $(0.0273)$ & $(0.0422)$ & $(0.0546)$ & $(0.0121)$ & $(0.00426)$ \\
Observations & & & & 9,172 & 4,974 \\
\hline
\end{tabular}

Note: The sample comprises all metropolitan statistical areas (MSAs) between January 2016 and August 2020. The dependent variable includes log number of homes sold, log new listings, log median house sale price, and log rental price. Apr-Jun is a dummy variable that is equal to 1 if the observation is between April and June 2020, and 0 otherwise. Jul-Aug is a dummy variable that is equal to 1 if the observation is between July and August 2020, and 0 otherwise. All specifications include year $\times$ month, MSA $\times$ year, and MSA $\times$ month fixed effects, and post-COVID month dummies $\times \log$ average case rate. Observations are weighted by the MSA's population. Standard errors are clustered at the MSA level: ${ }^{* * *} p<0.01,{ }^{* *} p<0.05,{ }^{*} p<0.1$. 


\section{Appendix}

\section{A1 Telework-Compatibility by $\mathrm{Su}(2020)$}

In the main analysis, we use the telework-compatibility indicator developed by Dingel and Neiman (2020). As a robustness check, we use an alternative telework indicator developed by $\mathrm{Su}(2020)$. $\mathrm{Su}$ uses a similar method to select telework-compatible occupations as Dingel and Neiman, with a slightly different and simpler set of criteria.

Specifically, $\mathrm{Su}$ assigns each occupation as either telework-compatible or not telework-compatible, based on five work context indices provided by $\mathrm{O}^{*} \mathrm{NET}$. An occupation is remote-compatible if five criteria are all met:

1. Work involves frequent use of email;

2. Work does not require physical proximity with other people closer than arm's length.

3. Work involves sitting at least half of the time.

4. Work does not involve significant kneeling, crouching, stooping or crawling.

5. Work does not involve significant bending, or twisting of the body.

The detailed selection criteria are listed as follows:

1. Work context variable "Electronic Mail" $\geq 87.5$. According to the scale of the index, an index of 75 means using email at least once a week and not every day. An index of 100 means using email every day. "Frequent use of email" is likely close to every day. However, since O*NET is estimated statistically from national surveys, $\mathrm{Su}$ takes an average between 75 and 100 as the cutoff value to allow some room for statistical error.

2. Work context variable "Physical Proximity" $\geq 75$. An index of 75 means physical proximity of an arm's length.

3. Work context variable "Spend Time Kneeling, Crouching, Stooping, or Crawling" $<50$.

4. Work context variable "Spend Time Bending or Twisting the Body" $<50$. 
The occupation code used is occ2010 defined in the IPUMS USA data. O*NET occupation codes are linked to occ2010 with a SOC-occ2010 crosswalk.

The regression results using $\mathrm{Su}$ is shown in Table $\mathrm{A} 3$. The magnitude of the coefficient on the log share of telework-compatible jobs does not vary much by either definition of telework-compatibility.

\section{A2 Regression with Online Views}

Alternative to the observed housing market outcomes, we can use the log number of online views of properties relative to the national average as the outcome variable. We obtain this variable from Realtor.com, which is a real estate listing website. The number of website views of properties could be an alternative measurement of housing demand. On the one hand, the number of views can be a better measure of housing demand since website views are not likely to be affected by the lockdown policies. On the other hand, the variable may introduce significant measurement error since

more views do not necessarily lead to more purchases. The results are shown in Table A2, Most of the estimates are not statistically significant, which could be because views are a rough measure of housing demand. Nevertheless, we find relative large and accurate estimates of the coefficients on interactions between After and log share of telework-compatible jobs, After and log pre-COVID house price, and After and log income. 


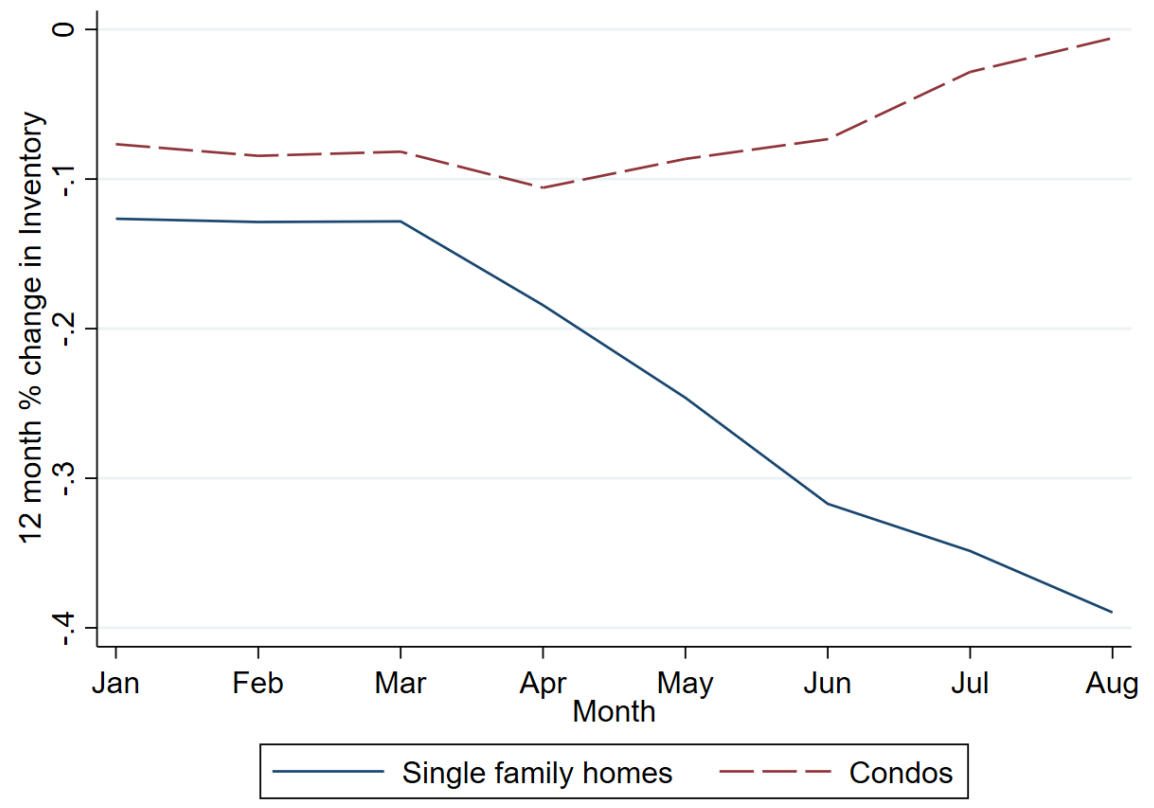

Figure A1: Inventory Growth: Single-Family Homes vs. Condominiums

Notes: The solid line represents the national home inventory for single-family homes. The dashed line represents the national home inventory for condominium. 


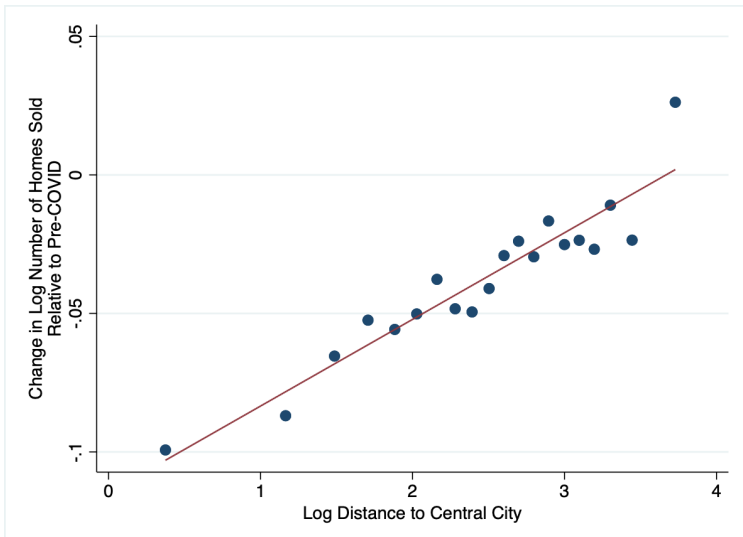

(a) Distance to the Central City

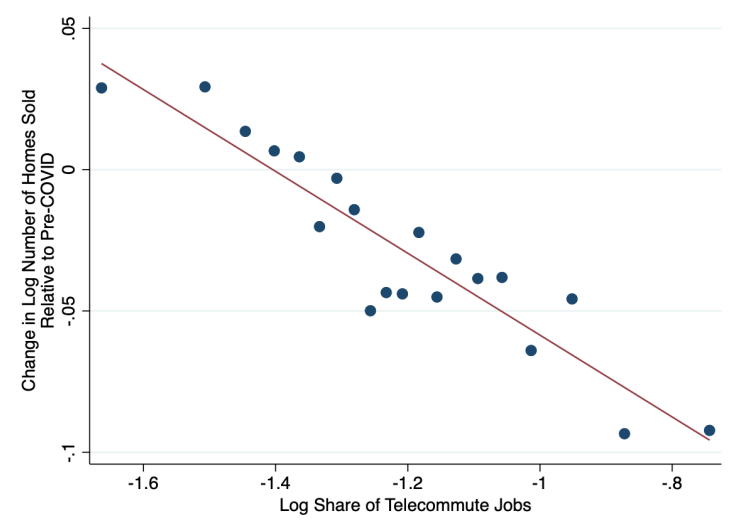

(c) Share of Telework-Compatible Jobs

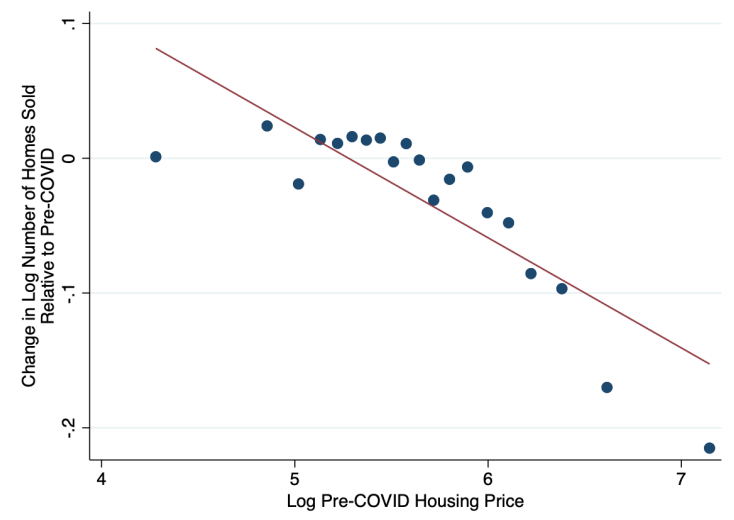

(e) Pre-COVID Housing Price

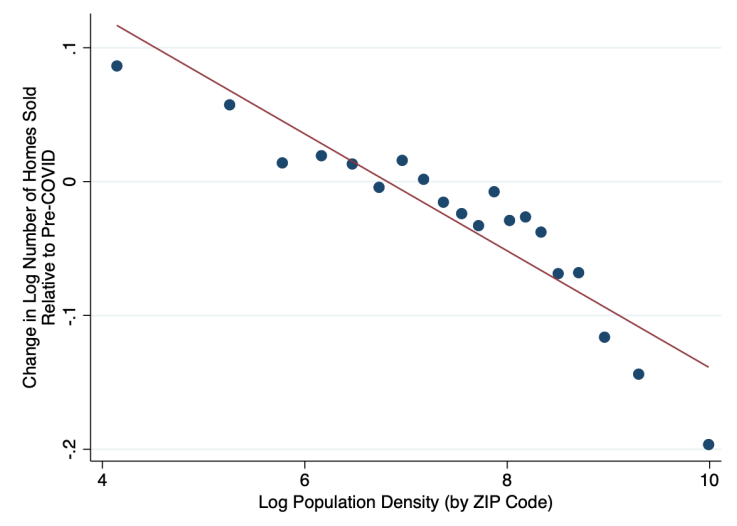

(b) Population Density

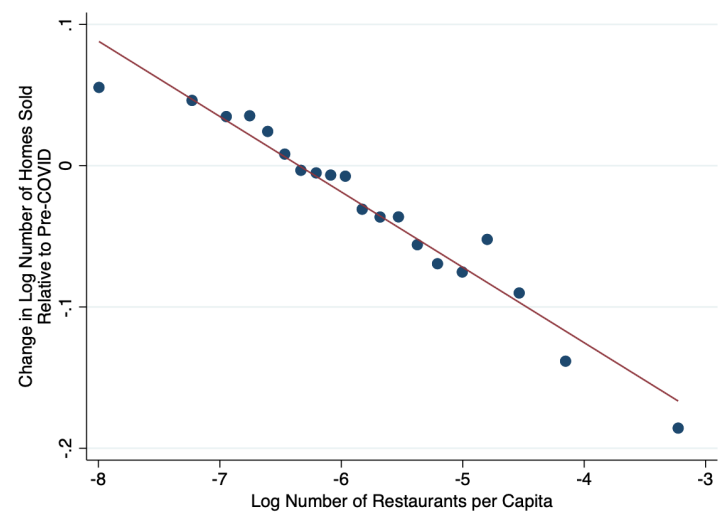

(d) Restaurants Per Capita

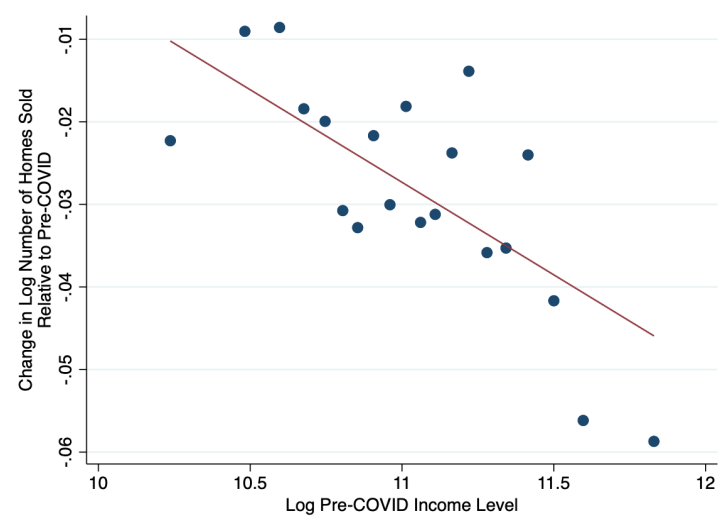

(f) Income

Figure A2: Changes in Log Home Sales (Relative to Pre-COVID-19) vs. Neighborhood Characteristics

Note: The figures present binned scatter plots of changes in log number of homes sold per month before and after the outbreak ( $y$-axis) vs. neighborhood characteristics by ZIP Code ( $x$-axis). We obtain ZIP code-level changes in $\log$ sales, controlling for MSA, time, ZIP code $\times$ month, and ZIP code $\times$ year fixed effects. To construct the figures, we divide the $x$ variable into 20 bins, and plot the mean values of $x$ and $y$ variables within each bin, controlling for county-level average case rate between April and August 2020. 


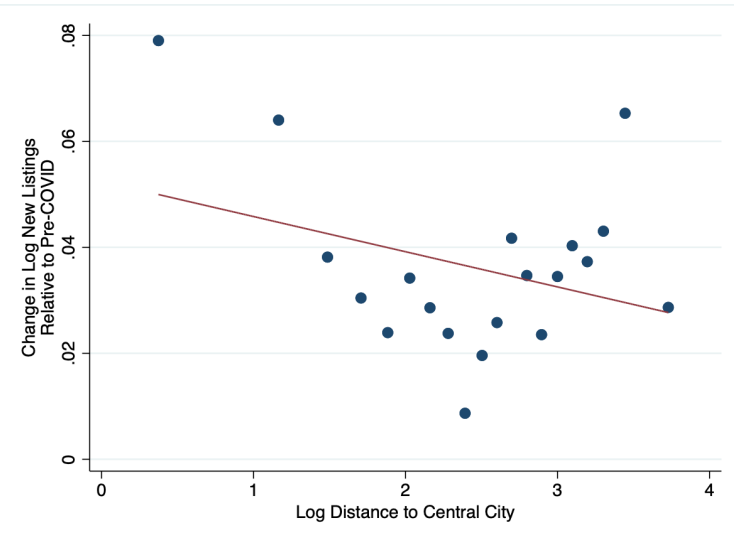

(a) Distance to the Central City

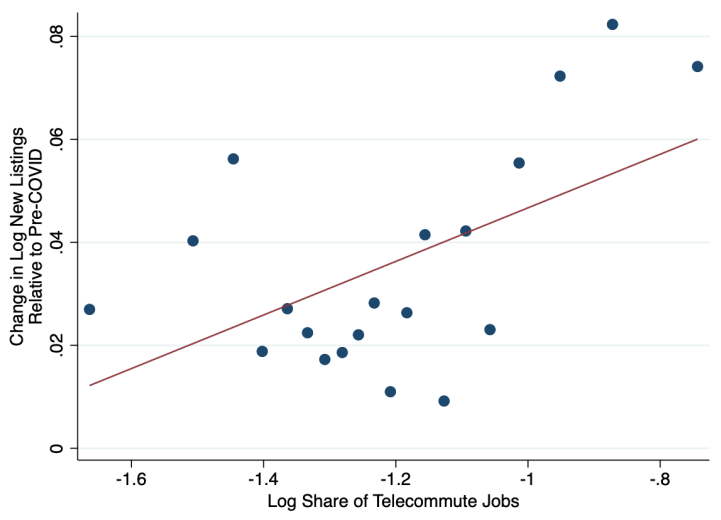

(c) Share of Telework-Compatible Jobs

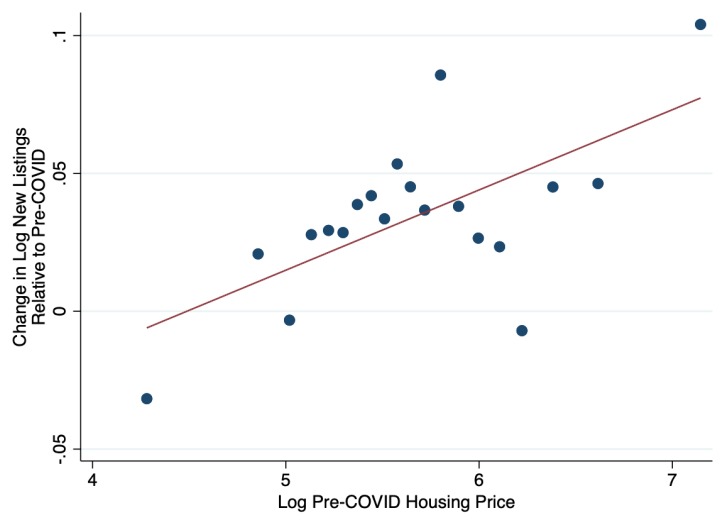

(e) Pre-COVID Housing Price

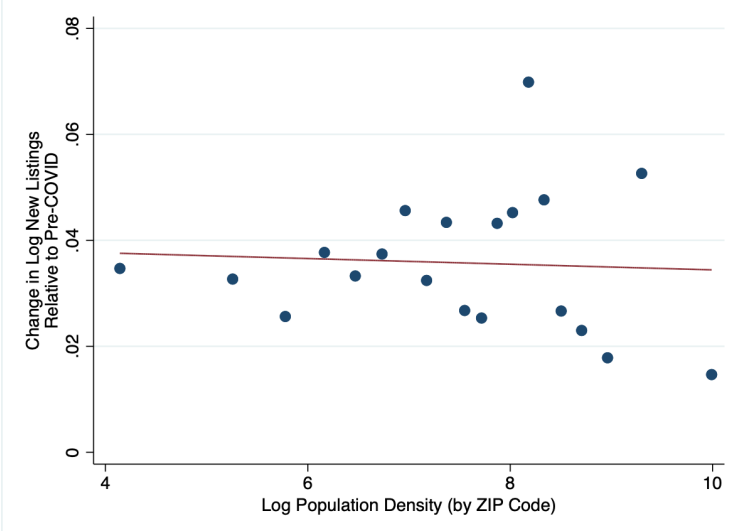

(b) Population Density

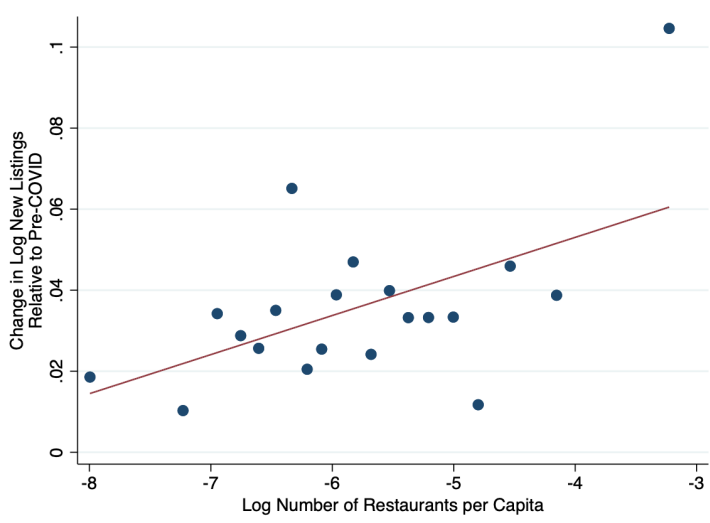

(d) Restaurants Per Capita

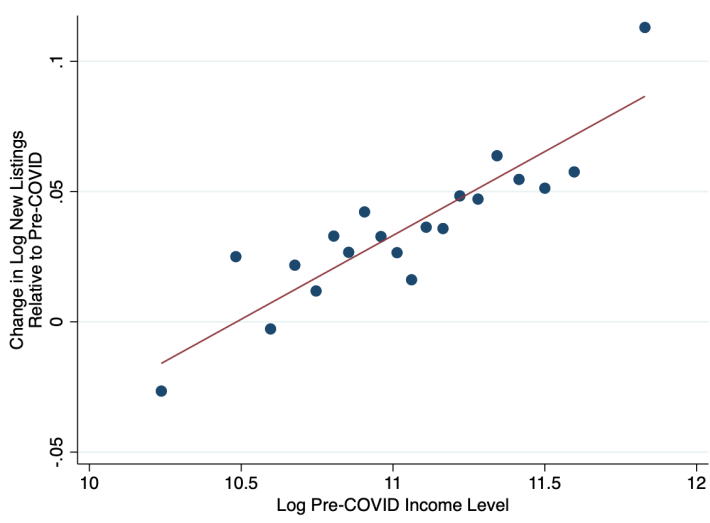

(f) Income

Figure A3: Changes in Log New Listings (Relative to Pre-COVID-19) vs. Neighborhood Characteristics

Note: The figures present binned scatter plots of changes in log number of new listings per month before and after the outbreak ( $y$-axis) vs. neighborhood characteristics by ZIP Code ( $x$-axis). We obtain ZIP code-level changes in $\log$ sales, controlling for MSA, time, ZIP code $\times$ month, and ZIP code $\times$ year fixed effects. To construct the figures, we divide the $x$ variable into 20 bins, and plot the mean values of $x$ and $y$ variables within each bin, controlling for county-level average case rate between April and August 2020. 


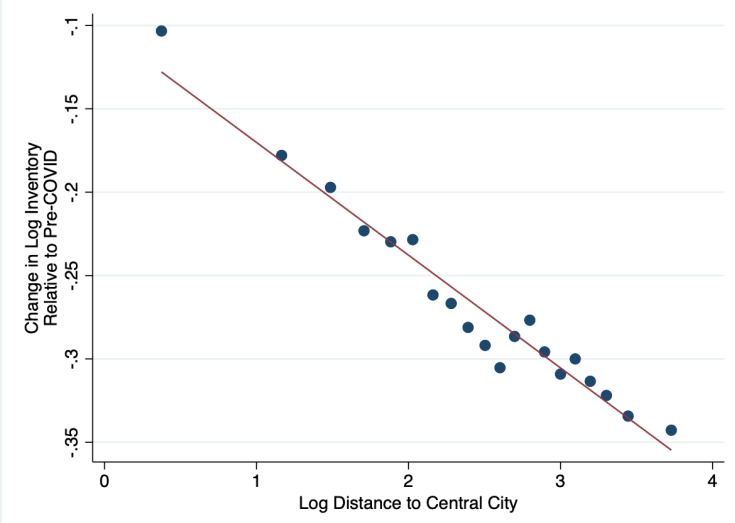

(a) Distance to the Central City

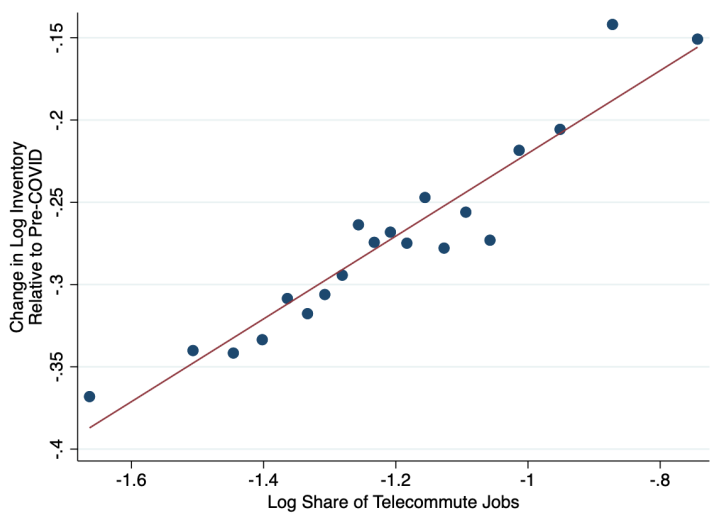

(c) Share of Telework-Compatible Jobs

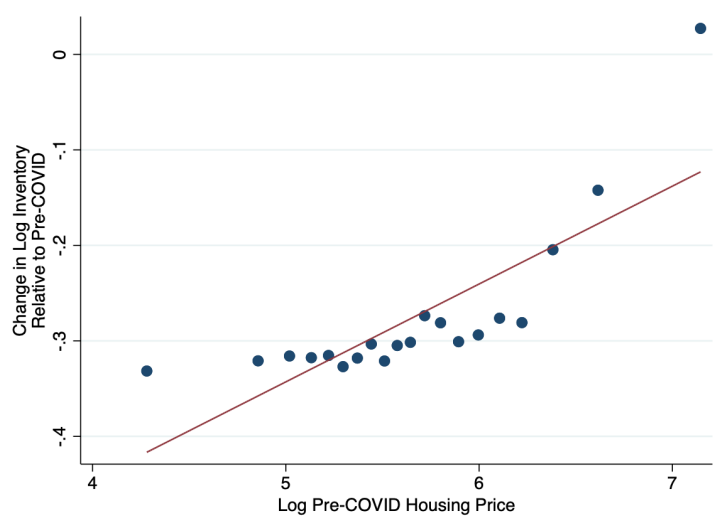

(e) Pre-COVID Housing Price

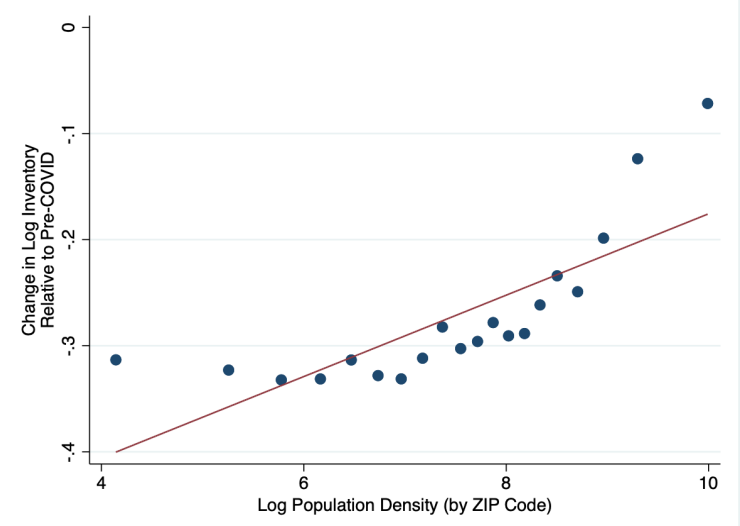

(b) Population Density

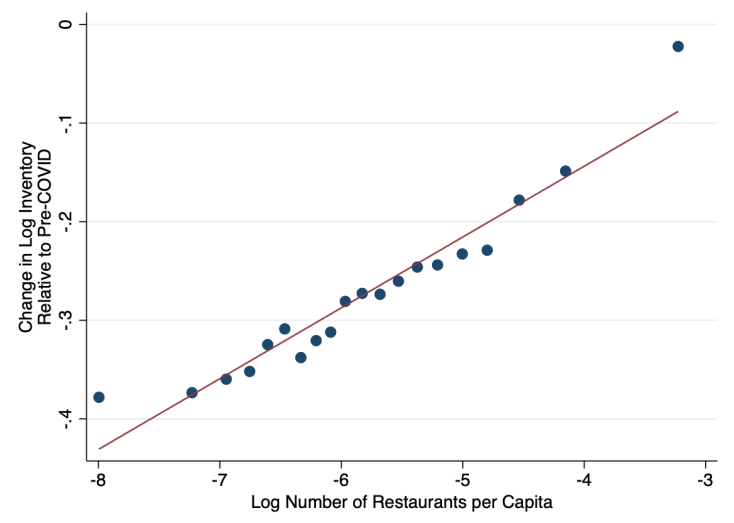

(d) Restaurants Per Capita

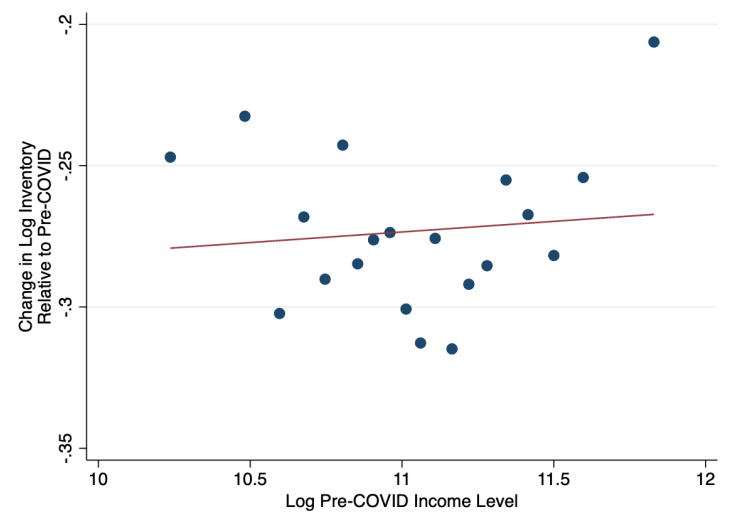

(f) Income

Figure A4: Changes in Log Inventory (Relative to Pre-COVID-19) vs. Neighborhood Characteristics

Note: The figures present binned scatter plots of changes in log inventory before and after the outbreak ( $y$-axis) vs. neighborhood characteristics by ZIP Code ( $x$-axis). We obtain ZIP code-level changes in log sales, controlling for MSA, time, ZIP code $\times$ month, and ZIP code $\times$ year fixed effects. To construct the figures, we divide the $x$ variable into 20 bins, and plot the mean values of $x$ and $y$ variables within each bin, controlling for county-level average case rate between April and August 2020. 


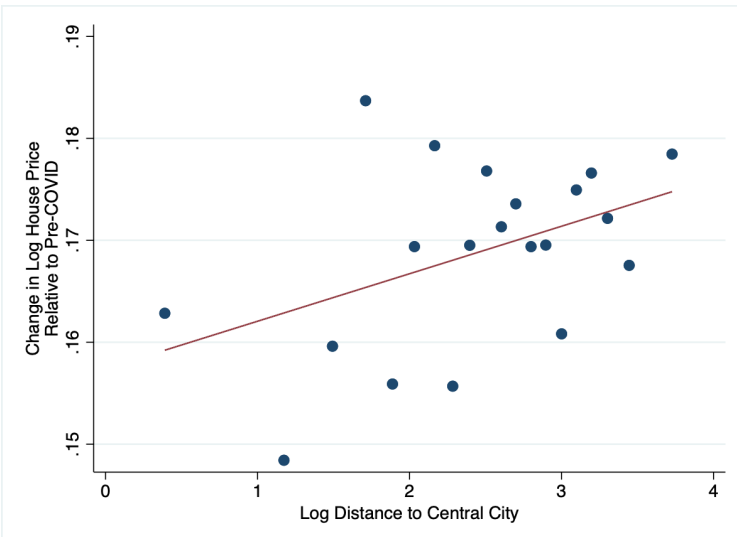

(a) Distance to the Central City

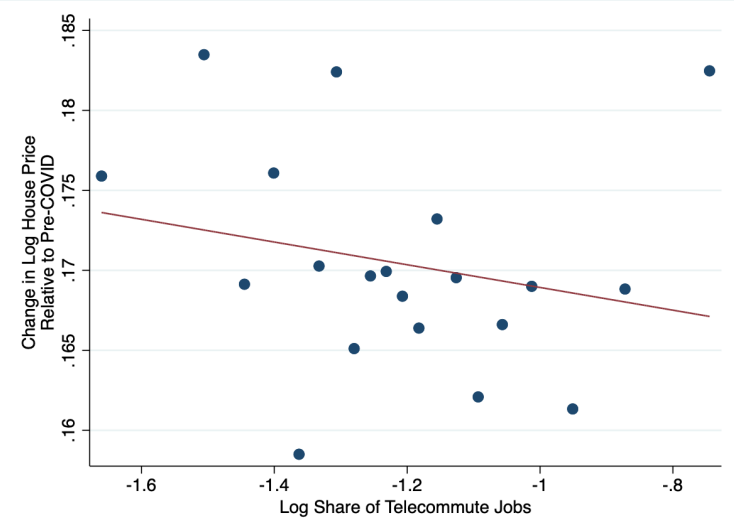

(c) Share of Telework-Compatible Jobs

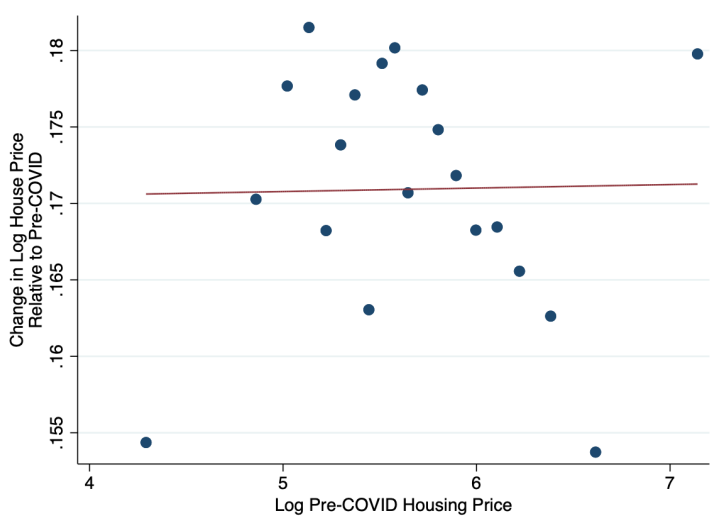

(e) Pre-COVID Housing Price

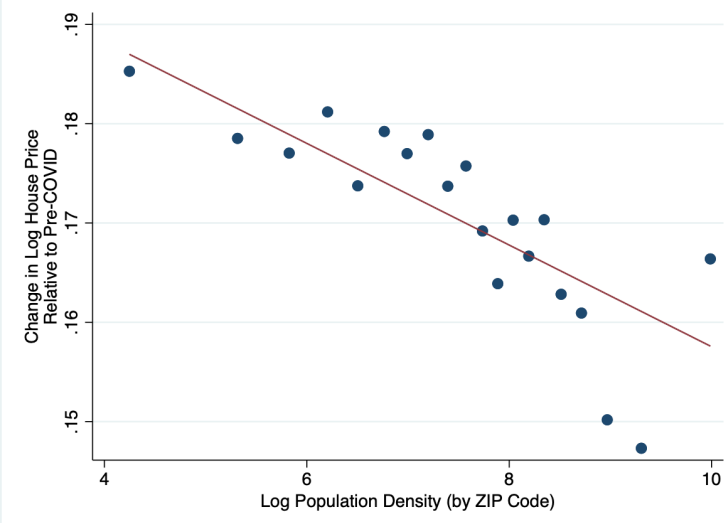

(b) Population Density

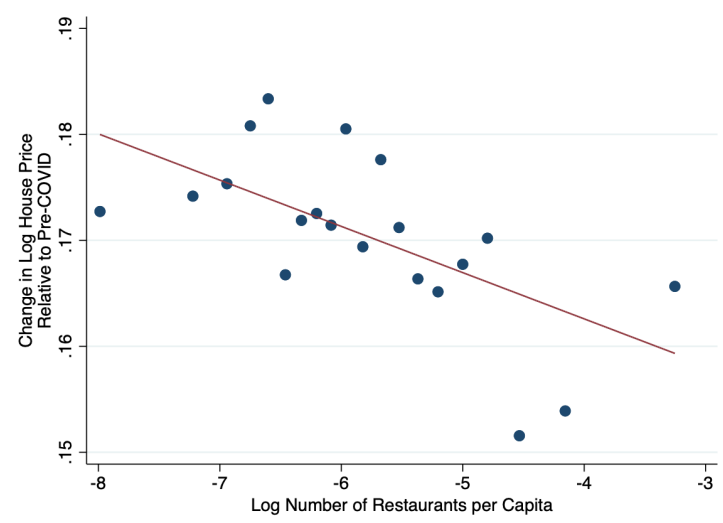

(d) Restaurants Per Capita

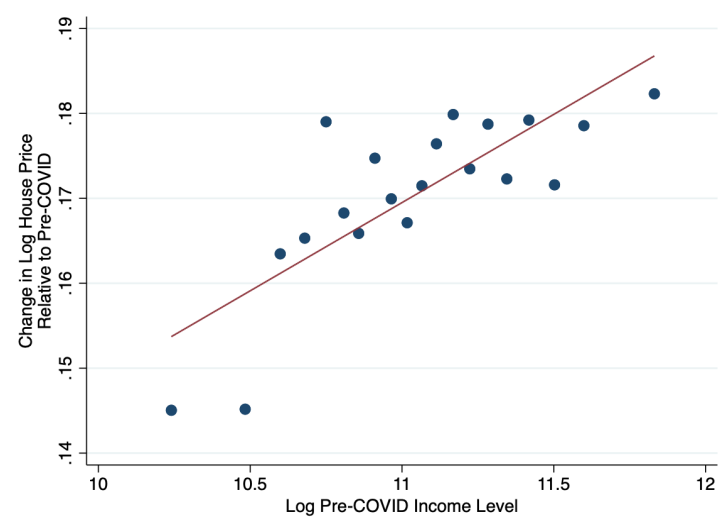

(f) Income

Figure A5: Changes in Log Home Value (Relative to Pre-COVID-19) vs. Neighborhood Characteristics

Note: The figures present binned scatter plots of changes in log home value before and after the outbreak ( $y$-axis) vs. neighborhood characteristics by ZIP Code ( $x$-axis). We obtain ZIP code-level changes in log sales, controlling for MSA, time, ZIP code $\times$ month, and ZIP code $\times$ year fixed effects. To construct the figures, we divide the $x$ variable into 20 bins, and plot the mean values of $x$ and $y$ variables within each bin, controlling for county-level average case rate between April and August 2020. 


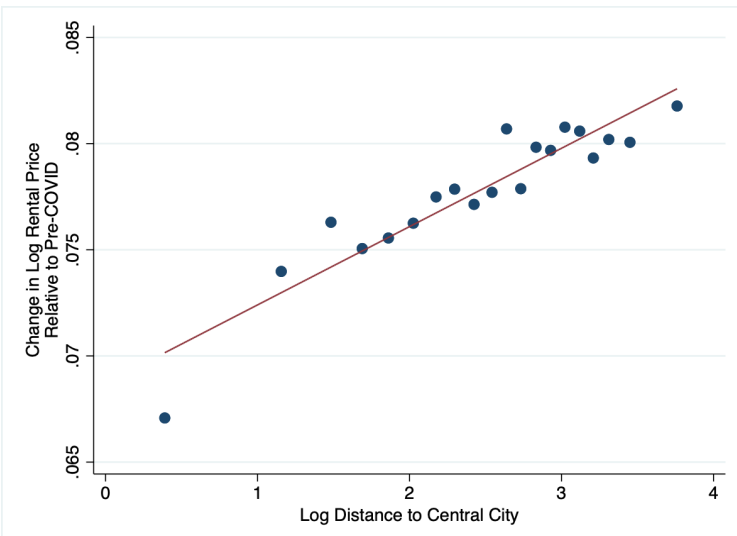

(a) Distance to the Central City

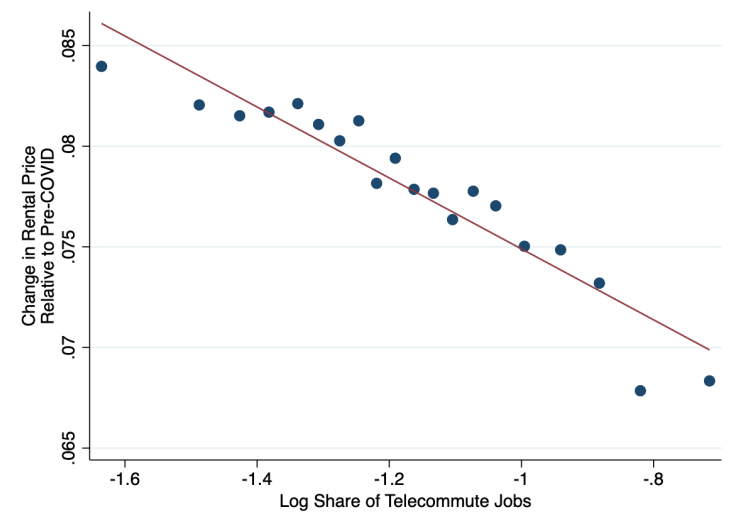

(c) Share of Telework-Compatible Jobs

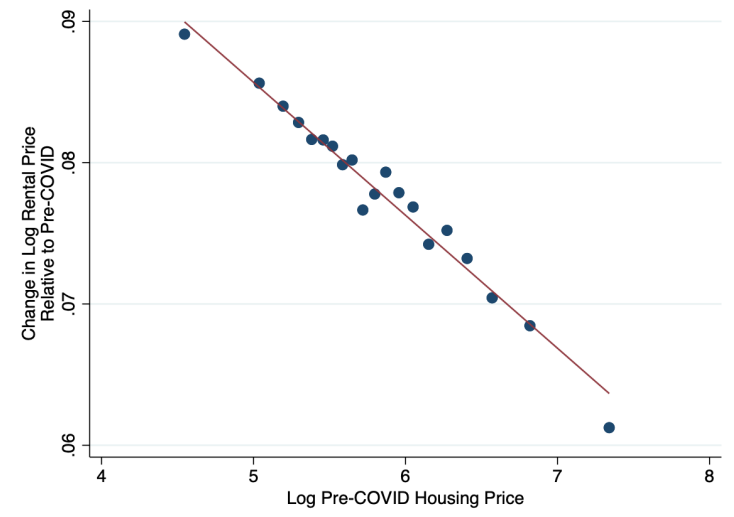

(e) Pre-COVID Housing Price

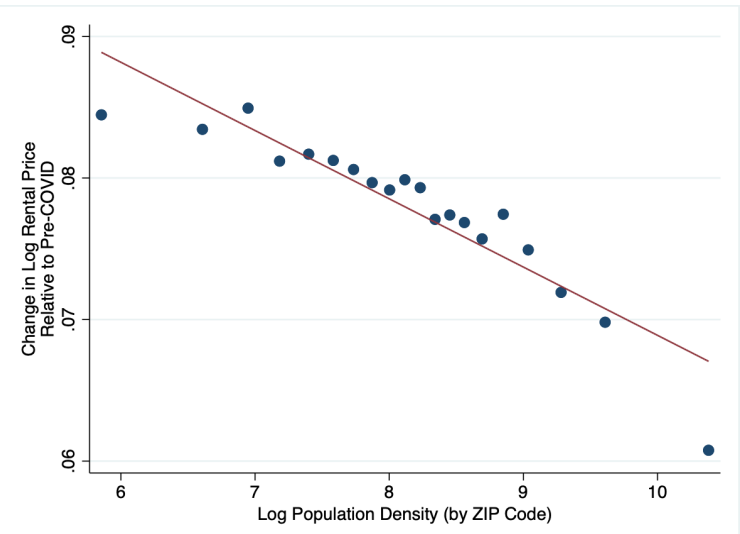

(b) Population Density

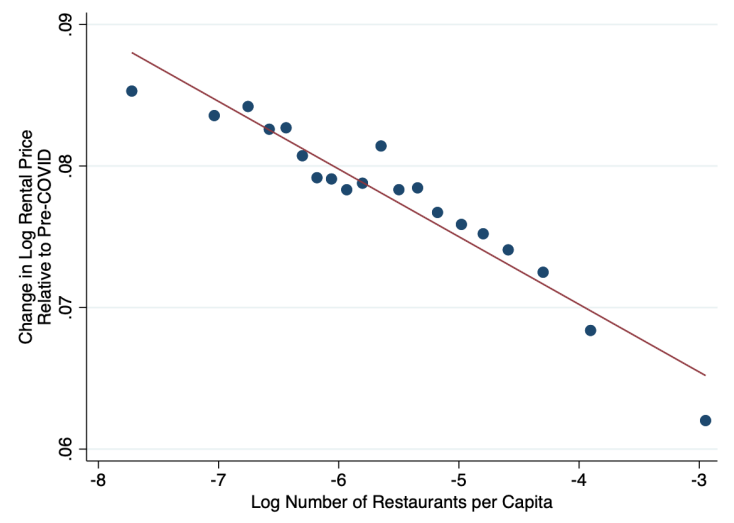

(d) Restaurants Per Capita

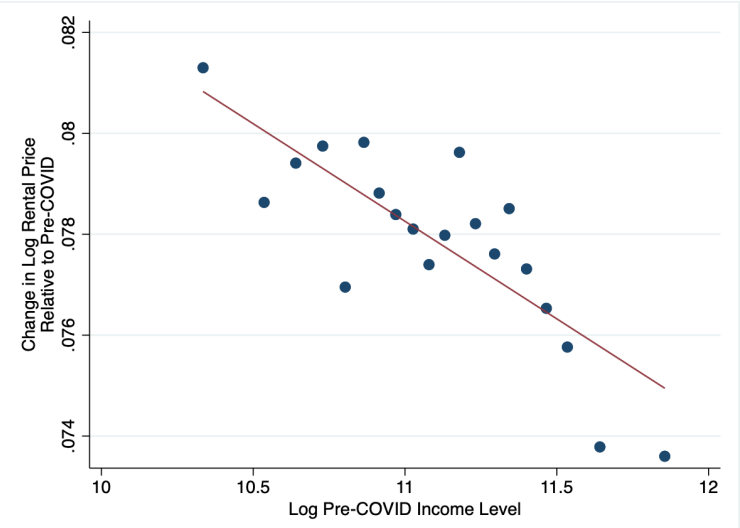

(f) Income

Figure A6: Changes in Log Rent (Relative to Pre-COVID-19) vs. Neighborhood Characteristics

Note: The figures present binned scatter plots of changes in log rent before and after the outbreak ( $y$-axis) vs. neighborhood characteristics by ZIP Code ( $x$-axis). We obtain ZIP code-level changes in log sales, controlling for MSA, time, ZIP code $\times$ month, and ZIP code $\times$ year fixed effects. To construct the figures, we divide the $x$ variable into 20 bins, and plot the mean values of $x$ and $y$ variables within each bin, controlling for county-level average case rate between April and August 2020. 
Table A1: Relationship Between Population Density and Other Neighborhood Characteristics

\begin{tabular}{|c|c|c|c|c|}
\hline & \multicolumn{4}{|c|}{ Log (Density) } \\
\hline & $(1)$ & $(2)$ & $(3)$ & $(4)$ \\
\hline Log (Distance to Downtown) & $\begin{array}{c}-0.673^{* * *} \\
(0.0204)\end{array}$ & $\begin{array}{c}-0.732^{* * *} \\
(0.0198)\end{array}$ & $\begin{array}{c}-0.849^{* * *} \\
(0.0185)\end{array}$ & $\begin{array}{c}-0.379^{* * *} \\
(0.0204)\end{array}$ \\
\hline Log (Transits per capita) & $\begin{array}{c}0.340^{* * *} \\
(0.0144)\end{array}$ & & & $\begin{array}{c}0.216^{* * *} \\
(0.0132)\end{array}$ \\
\hline Log (Jobs per capita) & & $\begin{array}{c}-0.183^{* * *} \\
(0.0285)\end{array}$ & & $\begin{array}{c}-0.285^{* * *} \\
(0.0289)\end{array}$ \\
\hline Log (Share of Telework-Compatible Jobs) & & $\begin{array}{c}0.246^{* * *} \\
(0.0565)\end{array}$ & & $\begin{array}{c}0.358^{* * *} \\
(0.0571)\end{array}$ \\
\hline Log (Restaurants per capita) & & $\begin{array}{c}0.502^{* * *} \\
(0.0283)\end{array}$ & & $\begin{array}{c}0.561 * * * \\
(0.0291)\end{array}$ \\
\hline Log (Pre-COVID House Price) & & & $\begin{array}{c}0.432^{* * *} \\
(0.0345)\end{array}$ & $\begin{array}{c}0.221^{* * *} \\
(0.0306)\end{array}$ \\
\hline Log (Income) & & & $\begin{array}{c}-0.573^{* * *} \\
(0.0478)\end{array}$ & $\begin{array}{c}-0.327^{* * *} \\
(0.0464)\end{array}$ \\
\hline Log (Share of Whites) & & & $\begin{array}{c}-0.231^{* * *} \\
(0.0182)\end{array}$ & $\begin{array}{c}-0.217^{* * *} \\
(0.0161)\end{array}$ \\
\hline Observations & 7,744 & 9,204 & 9,095 & 7,446 \\
\hline
\end{tabular}

Note: The sample comprises all ZIP codes. All columns include MSA fixed effects. Observations are weighted by the ZIP code's population. Robust standard errors in parentheses ${ }^{* * *} p<0.01$, ${ }^{* *} p<0.05,{ }^{*} p<0.1$. 
Table A2: Heterogeneous Effects of the COVID-19 Pandemic across ZIP Codes: Home Views

\begin{tabular}{|c|c|c|c|c|}
\hline & \multicolumn{4}{|c|}{ Log (Views) } \\
\hline & $(1)$ & $(2)$ & $(3)$ & $(4)$ \\
\hline \multirow[t]{2}{*}{ After $\times \log ($ Distance to Downtown $)$} & $0.0104^{* * *}$ & 0.00440 & 0.00593 & 0.00141 \\
\hline & $(0.00386)$ & $(0.00301)$ & $(0.00367)$ & $(0.00315)$ \\
\hline \multirow[t]{2}{*}{ After $\times \log$ (Density) } & -0.00376 & -0.000590 & -0.00167 & 0.000874 \\
\hline & $(0.00291)$ & $(0.00352)$ & $(0.00209)$ & $(0.00213)$ \\
\hline \multirow[t]{2}{*}{ After $\times$ Log $($ Jobs per capita $)$} & & -0.00311 & & -0.00405 \\
\hline & & $(0.00490)$ & & $(0.00485)$ \\
\hline \multirow[t]{2}{*}{ After $\times \log ($ Share of Telework Jobs $)$} & & $-0.0188^{*}$ & & $-0.0158^{*}$ \\
\hline & & $(0.0104)$ & & $(0.00920)$ \\
\hline \multirow[t]{2}{*}{ After $\times \log ($ restaurants per capita) } & & -0.00575 & & -0.00282 \\
\hline & & $(0.00528)$ & & $(0.00495)$ \\
\hline \multirow[t]{2}{*}{ After $\times \log ($ Pre-COVID Price $)$} & & & $-0.0332^{* * *}$ & $-0.0279 * * *$ \\
\hline & & & $(0.00789)$ & $(0.00647)$ \\
\hline \multirow[t]{2}{*}{ After $\times \log ($ Income $)$} & & & $0.0326^{* * *}$ & $0.0291^{* * *}$ \\
\hline & & & $(0.00851)$ & $(0.00910)$ \\
\hline \multirow[t]{2}{*}{ After $\times$ Log (Share of Whites) } & & & -0.000269 & 0.00176 \\
\hline & & & $(0.00518)$ & $(0.00523)$ \\
\hline Observations & 377,928 & 373,722 & 374,787 & 370,784 \\
\hline
\end{tabular}

Note: The sample comprises all ZIP Codes between January 2016 and August 2020, except April 2020. The dependent variable is the log number of views. After is a dummy variable that is equal to 1 if the observation is between April and August 2020, and 0 otherwise. All specifications include year $\times$ month, After $\times$ MSA, county $\times$ year, and county $\times$ month fixed effects, and After $\times \log$ average case rate. Observations are weighted by the ZIP code's population. Standard errors are clustered at the MSA level: *** $p<0.01,{ }^{* *} p<0.05,{ }^{*} p<0.1$. 
Table A3: Robustness Check: Using Telework-Compatibility Data from Su (2020)

\begin{tabular}{|c|c|c|c|c|c|}
\hline & Log (Sales) & Log (New Listings) & Log (Inventory) & Log (Price) & $\log ($ Rent $)$ \\
\hline & (1) & $(2)$ & $(3)$ & (4) & $(5)$ \\
\hline \multirow[t]{2}{*}{ After $\times \log ($ Distance to Downtown $)$} & $0.0135^{* * *}$ & $-0.0155^{* *}$ & $-0.0276^{* * *}$ & -0.00131 & 0.000683 \\
\hline & $(0.00441)$ & $(0.00787)$ & $(0.00662)$ & $(0.00498)$ & $(0.000466)$ \\
\hline \multirow{2}{*}{ After $\times \log ($ Density $)$} & $-0.0213^{* * *}$ & -0.00393 & 0.00496 & -0.000269 & $-0.00195^{* * *}$ \\
\hline & $(0.00527)$ & $(0.00692)$ & $(0.00549)$ & $(0.00201)$ & $(0.000342)$ \\
\hline \multirow[t]{2}{*}{ After $\times \log ($ Jobs per capita $)$} & 0.00342 & $0.0185^{* *}$ & 0.0149 & 0.00197 & $-0.00198^{* * *}$ \\
\hline & $(0.00576)$ & $(0.00731)$ & $(0.00924)$ & $(0.00471)$ & $(0.000646)$ \\
\hline \multirow[t]{2}{*}{ After $\times$ Log (Share of Telework Jobs) } & $-0.0427^{* * *}$ & -0.00868 & $0.0811^{* * *}$ & 0.000327 & $-0.00522^{* * *}$ \\
\hline & $(0.0141)$ & $(0.0260)$ & $(0.0194)$ & $(0.00850)$ & $(0.00123)$ \\
\hline \multirow[t]{2}{*}{ After $\times \log$ (restaurants per capita) } & -0.00875 & -0.00305 & $0.0201^{* *}$ & -0.00356 & 0.00102 \\
\hline & $(0.00569)$ & $(0.00697)$ & $(0.00961)$ & $(0.00575)$ & $(0.000622)$ \\
\hline \multirow[t]{2}{*}{ After $\times$ Log $($ Pre-COVID Price $)$} & $-0.0529^{* * *}$ & 0.0192 & $0.114^{* * *}$ & -0.00285 & $-0.00717^{* * *}$ \\
\hline & $(0.00747)$ & $(0.0271)$ & $(0.0215)$ & $(0.00731)$ & $(0.000823)$ \\
\hline \multirow[t]{2}{*}{ After $\times \log ($ Income $)$} & $0.0219 *$ & 0.0443 & $-0.109^{* * *}$ & $0.0201^{* *}$ & $0.00460^{* * *}$ \\
\hline & $(0.0113)$ & $(0.0285)$ & $(0.0238)$ & $(0.00888)$ & $(0.00119)$ \\
\hline \multirow[t]{2}{*}{ After $\times$ Log (Share of Whites) } & 0.00179 & $0.0301^{* * *}$ & $0.0233^{* * *}$ & $0.00594^{*}$ & $-0.000996^{* *}$ \\
\hline & $(0.00457)$ & $(0.00617)$ & $(0.00603)$ & $(0.00357)$ & $(0.000418)$ \\
\hline
\end{tabular}


Note: The sample comprises all ZIP codes between January 2016 and August 2020. The dependent variable is the log number of homes sold. After is a dummy variable that is equal to 1 if the observation is between April and August 2020, and 0 otherwise. All specifications include year $\times$ month, After $\times$ MSA, county $\times$ year, and county $\times$ month fixed effects, and After $\times \log$ average case rate. The number of jobs per capita and the share of jobs within 3 miles of a ZIP code are estimated using data from $\operatorname{Su}(2020)$. Observations are weighted by the ZIP code's population. Standard errors are clustered at the MSA level: ${ }^{* * *} p<0.01,{ }^{* *} p<0.05,{ }^{*} p<0.1$. 